Article

\title{
Synthesis and Bioactivity of 5-Substituted-2-furoyl Diacylhydazide Derivatives with Aliphatic Chain
}

\author{
Zining Cui ${ }^{1,2, *}$, Xinghai $\mathrm{Li}^{3}$, Fang Tian ${ }^{2}$ and Xiaojing Yan ${ }^{2, *}$
}

1 Guangdong Province Key Laboratory of Microbial Signals and Disease Control, Department of Plant Pathology, College of Natural Resources and Environment, South China Agricultural University, Guangzhou 510642, China

2 State Key Laboratory for Biology of Plant Diseases and Insect Pests, Institute of Plant Protection, Chinese Academy of Agricultural Sciences, Beijing 100193, China; E-Mail: ftian@ippcaas.cn

3 Department of Pesticide Science, Plant Protection College, Shenyang Agricultural University, Shenyang 110866, China; E-Mail: xinghai30@163.com

* Authors to whom correspondence should be addressed;

E-Mails: ziningcui@scau.edu.cn (Z.C.); yanxjcau@gmail.com (X.Y.);

Tel./Fax: +86-20-8528-8229 (Z.C.).

Received: 24 March 2014; in revised form: 2 May 2014 / Accepted: 5 May 2014 /

Published: 20 May 2014

\begin{abstract}
A series of 5-substituted-2-furoyl diacylhydazide derivatives with aliphatic chain were designed and synthesized. Their structures were characterized by IR, ${ }^{1} \mathrm{H}$ NMR, elemental analysis, and X-ray single crystal diffraction. The anti-tumor bioassay revealed that some title compounds exhibited promising activity against the selected cancer cell lines, especially against the human promyelocytic leukemic cells (HL-60). Their fungicidal tests indicated that most of the title compounds showed significant anti-fungal activity. The preliminary structure-activity relationship showed that the aliphatic chain length and differences in the $\mathrm{R}^{2}$ group had obvious effects on the anti-tumor and anti-fungal activities. The bioassay results demonstrated that the title compounds hold great promise as novel lead compounds for further drug discovery.
\end{abstract}

Keywords: diacylhydrazide; aliphatic chain; synthesis; bioactivity 


\section{Introduction}

Hydrazides, a group of peptide mimicking molecules with amide group and flexible conformation, have been applied in medicine since the early 1950s, when isoniazid was used as a therapeutic agent against Mycobacterium tuberculosis [1,2]. Later studies discovered their diverse bioactivities as antituberculous agents [3,4], human immunodeficiency virus (HIV) inhibitors [5], inhibitors of microperoxidase [6] and glycogen phosphorylase [7], and pesticides [8-10]. Hydrazides are also key intermediates, especially in the preparation of pharmaceuticals and agrochemicals. Their synthesis has attracted significant attention due to their application as scaffolds in the construction of many nitrogen containing heterocycles, such as 1,2,4-triazoles [11], 1,3,4-oxadiazoles [12,13], 1,3,4-thiadiazoles [14], 1,2,4,5-tetrazines [15], etc.

In our previous study, we found that 5-phenyl-2-furoyl diacylhydrazides containing aromatic rings (IV) [16-22] not only exhibited anti-tumor activity, but also fungicidal and insecticidal activity. In order to discover compounds with better bioactivities, we replaced the rigid aromatic rings (IV) with the flexible aliphatic chains (III), as shown in Scheme 1. A series of 5-phenyl-2-furoyl diacylhydrazides bearing different aliphatic chains were designed and synthesized by the route shown in Scheme 2. Their anti-tumor, anti-fungal, and insecticidal activities were evaluated. The structure-activity relationships were elucidated.

Scheme 1. Design strategy for title compounds.

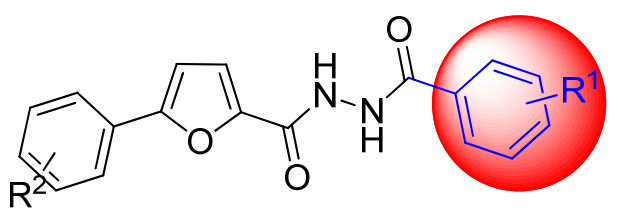

IV

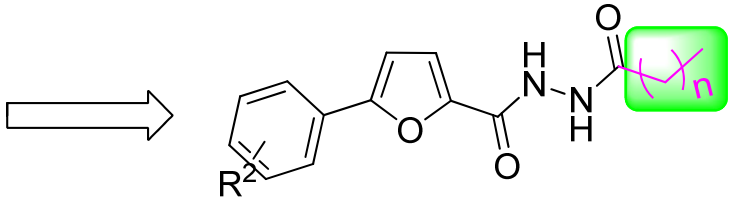

III

Scheme 2. General synthesis procedure for title compounds III. III-1-1: $\mathrm{R}^{1}=\mathrm{CH}_{3}$, $\mathrm{R}^{2}=2-\mathrm{Cl}$; III-2-1: $\mathrm{R}^{1}=\mathrm{CH}_{3}, \mathrm{R}^{2}=3-\mathrm{Cl}$; III-3-1: $\mathrm{R}^{1}=\mathrm{CH}_{3}, \mathrm{R}^{2}=4-\mathrm{Cl}$; III-4-1: $\mathrm{R}^{1}=\mathrm{CH}_{3}$, $\mathrm{R}^{2}=2-\mathrm{F}$; III-5-1: $\mathrm{R}^{1}=\mathrm{CH}_{3}, \mathrm{R}^{2}=3-\mathrm{F}$; III-6-1: $\mathrm{R}^{1}=\mathrm{CH}_{3}, \mathrm{R}^{2}=4-\mathrm{F}$; III-7-1: $\mathrm{R}^{1}=\mathrm{CH}_{3}$, $\mathrm{R}^{2}=2$,4-di-F; III-8-1: $\mathrm{R}^{1}=\mathrm{CH}_{3}, \mathrm{R}^{2}=2,6-$ di-F; III-9-1: $\mathrm{R}^{1}=\mathrm{CH}_{3}, \mathrm{R}^{2}=2-\mathrm{NO}_{2}$; III-10-1: $\mathrm{R}^{1}=\mathrm{CH}_{3}, \mathrm{R}^{2}=3-\mathrm{NO}_{2}$; III-11-1: $\mathrm{R}^{1}=\mathrm{CH}_{3}, \mathrm{R}^{2}=4-\mathrm{NO}_{2} ;$ III-12-1: $\mathrm{R}^{1}=\mathrm{CH}_{3}, \mathrm{R}^{2}=\mathrm{H}$; III-13-1: $\mathrm{R}^{1}=\mathrm{CH}_{3}, \mathrm{R}^{2}=4-\mathrm{CH}_{3}$; III-14-1: $\mathrm{R}^{1}=\mathrm{CH}_{3}, \mathrm{R}^{2}=4-\mathrm{OCH}_{3}$; III-15-1: $\mathrm{R}^{1}=\mathrm{CH}_{3}$, $\mathrm{R}^{2}=4-\mathrm{Br}$; III-3-2: $\mathrm{R}^{1}=\mathrm{CH}_{2} \mathrm{CH}_{3}, \mathrm{R}^{2}=4-\mathrm{Cl}$; III-3-3: $\mathrm{R}^{1}=n-\mathrm{C}_{3} \mathrm{H}_{7}, \mathrm{R}^{2}=4-\mathrm{Cl}$; III-3-4: $\mathrm{R}^{1}=i-\mathrm{C}_{3} \mathrm{H}_{7}, \mathrm{R}^{2}=4-\mathrm{Cl}$; III-3-5: $\mathrm{R}^{1}=n-\mathrm{C}_{5} \mathrm{H}_{11}, \mathrm{R}^{2}=4-\mathrm{Cl}$; III-3-6: $\mathrm{R}^{1}=n-\mathrm{C}_{6} \mathrm{H}_{13}, \mathrm{R}^{2}=4-\mathrm{Cl}$; III-3-7: $\mathrm{R}^{1}=n-\mathrm{C}_{7} \mathrm{H}_{15}, \mathrm{R}^{2}=4-\mathrm{Cl}$; III-3-8: $\mathrm{R}^{1}=n-\mathrm{C}_{8} \mathrm{H}_{17}, \mathrm{R}^{2}=4-\mathrm{Cl}$; III-3-9: $\mathrm{R}^{1}=n-\mathrm{C}_{9} \mathrm{H}_{19}$, $\mathrm{R}^{2}=4-\mathrm{Cl}$.

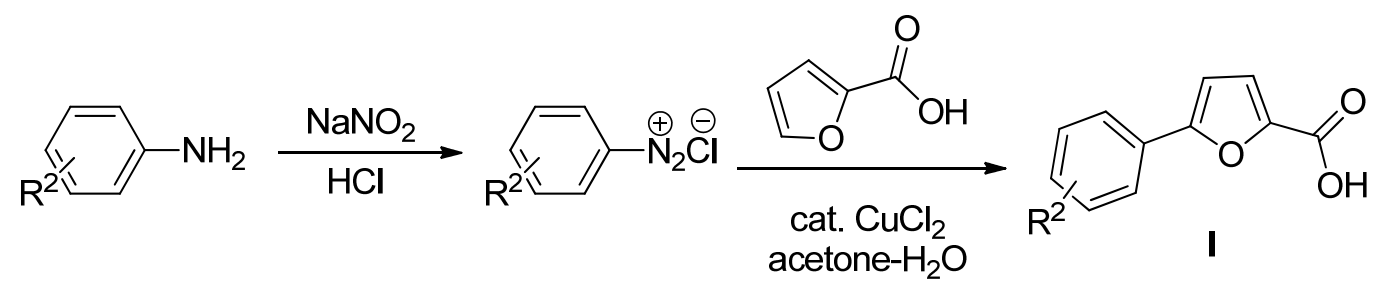


Scheme 2. Cont.

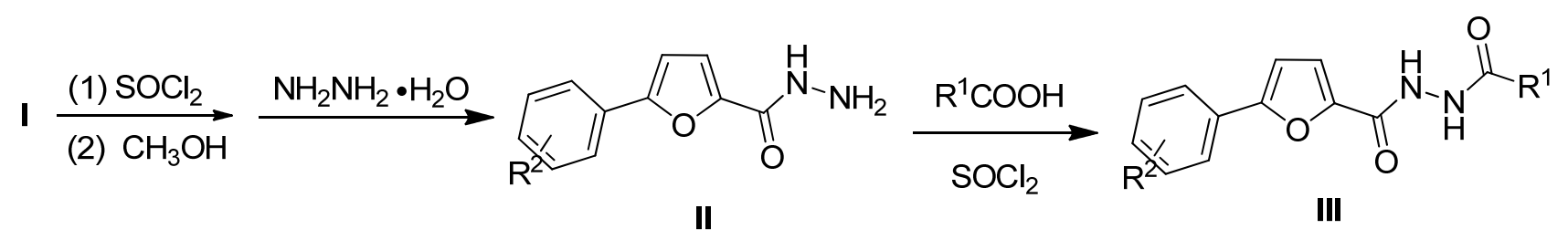

\section{Results and Discussion}

\subsection{Synthesis and Structure Elucidation}

By utilizing the method of Meerwein arylation with copper(II)-catalyzed decomposition of diazonium salts, a series of 5-substituted phenyl-2-furoic acid I were prepared in good yields, based on substituted anilines and furoic acid as starting reagents. The nucleophilic reaction with 2-furoic acid exhibited a high region-selectivity at the 5-position of the furan ring. Then the 5-substituted phenyl-2-furoyl hydrazides II were prepared as previously described [16-22], and subsequently reacted with different aliphatic acids and thionyl chloride to obtain the title compounds. The synthesis route of title compounds III is shown in Scheme 2.

All the structures of the title compounds were confirmed by IR, ${ }^{1} \mathrm{H}$ NMR, and elemental analyses. In the IR spectra, the compounds showed absorption bands around $3300 \mathrm{~cm}^{-1}$, originating from the $\mathrm{N}-\mathrm{H}$ stretching vibration. The strong bands around $1680 \mathrm{~cm}^{-1}$ could be assigned to the $\mathrm{C}=\mathrm{O}$ stretching vibration. The bands around $1620 \mathrm{~cm}^{-1}$ were attributed to the secondary amide. Absorption bands around 1510 and $1480 \mathrm{~cm}^{-1}$ were attributed to the frame vibration of the phenyl and furan rings.

In the ${ }^{1} \mathrm{H}$ NMR spectra, one or two sharp peaks in the range from 10.30 to $10.80 \mathrm{ppm}$ were due to the presence of hydrazine. Mostly, the signals for protons on the phenyl rings appeared as multiplets in the range from 7.10 to $8.20 \mathrm{ppm}$ and the signals for protons on the furan ring were split into two doublets in the range from 6.90 to $7.05 \mathrm{ppm}$. All the proton signals of the aliphatic chain appeared in the high field around 0.80 to $2.20 \mathrm{ppm}$.

The crystal data and structure are presented in Table 1 and Figure 1, and allowed a perspective view of compound III-3-2. Some important bond lengths, angels, and torsion angles of compound III-3-2 are given in Table 2. It can be seen from the X-ray single crystal analysis of III-3-2 that the distance of single bonds $\mathrm{C} 11-\mathrm{N} 1$ and $\mathrm{C} 12-\mathrm{N} 2(1.355(6)$ and $1.343(6) \AA)$ were equal to the $\mathrm{C}-\mathrm{N}$ double bond $(1.35 \AA)$, the single bonds $\mathrm{C} 4-\mathrm{C} 7$ and $\mathrm{C} 10-\mathrm{C} 11$ (1.455(6) and 1.465(6) $\AA$ ) were shorter than the standard $\mathrm{C}-\mathrm{C}$ single bond $(1.54 \AA)$, but longer than the $\mathrm{C}-\mathrm{C}$ double bond $(1.34 \AA)$. N1-N2 $(1.396(5) \AA)$ single bonds was shorter than the standard $\mathrm{N}-\mathrm{N}$ single bond (1.45 $\AA$ ), but longer than $\mathrm{N}-\mathrm{N}$ double bond $(1.25 \AA)$. These results clearly indicated that the p orbital of the $\mathrm{N}$ atoms conjugated with the $\pi$ molecular orbital and formed the delocalized $\pi$-bonds with the conjoint furan and benzene ring. However, unexpectedly, the p orbitals of N1 and N2 seemed not to be conjugated with the $\pi$ molecular orbital of the $\mathrm{C} 11-\mathrm{O} 2$ and $\mathrm{C} 12-\mathrm{O} 3$ double bonds, which was explained by the bond length of $\mathrm{C} 11-\mathrm{O} 2$ and $\mathrm{C} 12-\mathrm{O} 3(1.238(5)$ and 1.218(5) $\AA$ ) that followed the normal range for $\mathrm{C}-\mathrm{O}$ double bond lengths (1.19-1.23 $\AA$ ). 
Figure 1. Molecular structure of compound III-3-2, showing 30\% probability ellipsoids; $\mathrm{H}$ atoms are shown as small spheres of arbitrary radii.

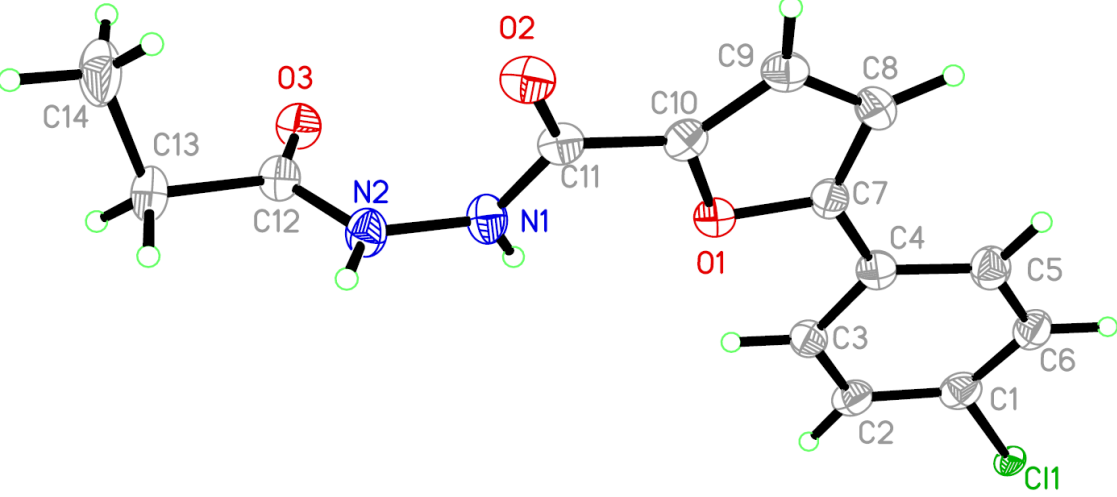

Table 1. Crystal and experimental data of compound III-3-2.

\begin{tabular}{|c|c|}
\hline Empirical formula & $\mathrm{C}_{14} \mathrm{H}_{13} \mathrm{CIN}_{2} \mathrm{O}_{3}$ \\
\hline Formula weight & 292.71 \\
\hline$T$ & $113(2) \mathrm{K}$ \\
\hline Wavelength & $0.71070 \AA$ \\
\hline Crystal system & Orthorhombic \\
\hline \multirow[t]{2}{*}{ Space group } & C 2221 \\
\hline & $a=8.4488(4) \AA, \alpha=90^{\circ}$ \\
\hline \multirow[t]{2}{*}{ Unit cell dimensions } & $b=20.1074(13) \AA, \beta=90^{\circ}$ \\
\hline & $c=16.1363(10) \AA, \gamma=90^{\circ}$ \\
\hline Volume & $2741.3(3) \AA^{3}$ \\
\hline$Z$ & 8 \\
\hline$D_{x}$ & $1.418 \mathrm{mg} \cdot \mathrm{m}^{-3}$ \\
\hline Absorption coefficient & $0.287 \mathrm{~mm}^{-1}$ \\
\hline$F\left(\begin{array}{lll}0 & 0 & 0\end{array}\right)$ & 1216 \\
\hline Crystal dimensions & $0.22 \times 0.20 \times 0.20 \mathrm{~mm}$ \\
\hline$\theta$ range for data collection & 2.03 to 27.85 \\
\hline Completeness to $\theta=27.85$ & $99.9 \%$ \\
\hline Limiting indices & $-11 \leq h \leq 10,-26 \leq k \leq 23,-21 \leq l \leq 21$ \\
\hline Reflection collected/unique & $12970 / 3269[R(\mathrm{int})=0.0486]$ \\
\hline Absorption correction & Semi-empirical from equivalents \\
\hline Max. and min. transmission & 0.9448 and 0.9395 \\
\hline Data/restraints/parameters & $3269 / 0 / 184$ \\
\hline Goodness-of-fit on $F^{2}$ & 1.101 \\
\hline Final $R$ indices $[I>2 \sigma(I)]$ & $R_{1}=0.0693, \mathrm{w} R_{2}=0.1949$ \\
\hline $2 \theta_{\max }$ & $55.7^{\circ}$ with Mo $K_{\alpha}$ \\
\hline$(\Delta \rho)_{\max }$ & $1.204 \mathrm{e} \AA^{-3}$ \\
\hline$(\Delta \rho)_{\min }$ & $-0.406 \mathrm{e}^{-3}$ \\
\hline Program system & SHELXS-97, SHELXL-97 \\
\hline Structure determination & Direct method \\
\hline Refinement & Full-matrix least-squares on $F^{2}$ \\
\hline CCDC No. & 935116 \\
\hline
\end{tabular}


Table 2. Selected bond lengths, angels, and torsion angles of compound III-3-2.

\begin{tabular}{cccccc}
\hline Lengths & $(\mathbf{\AA})$ & Angles & $\mathbf{(}^{\circ}$ & Torsion angles & $\mathbf{(}^{\circ}$ \\
\hline $\mathrm{Cl}(1)-\mathrm{C}(1)$ & $1.825(5)$ & $\mathrm{C}(11)-\mathrm{N}(1)-\mathrm{N}(2)$ & $118.4(4)$ & $\mathrm{C}(11)-\mathrm{N}(1)-\mathrm{N}(2)-\mathrm{C}(12)$ & $102.3(5)$ \\
$\mathrm{N}(1)-\mathrm{C}(11)$ & $1.355(6)$ & $\mathrm{C}(12)-\mathrm{N}(2)-\mathrm{N}(1)$ & $120.2(4)$ & $\mathrm{C}(6)-\mathrm{C}(1)-\mathrm{C}(2)-\mathrm{C}(3)$ & $2.3(7)$ \\
$\mathrm{N}(1)-\mathrm{N}(2)$ & $1.396(5)$ & $\mathrm{C}(10)-\mathrm{O}(1)-\mathrm{C}(7)$ & $106.8(4)$ & $\mathrm{Cl}(1)-\mathrm{C}(1)-\mathrm{C}(2)-\mathrm{C}(3)$ & $-177.6(3)$ \\
$\mathrm{N}(2)-\mathrm{C}(12)$ & $1.343(6)$ & $\mathrm{C}(2)-\mathrm{C}(1)-\mathrm{Cl}(1)$ & $119.1(4)$ & $\mathrm{O}(1)-\mathrm{C}(7)-\mathrm{C}(8)-\mathrm{C}(9)$ & $2.5(5)$ \\
$\mathrm{O}(1)-\mathrm{C}(10)$ & $1.364(5)$ & $\mathrm{O}(1)-\mathrm{C}(7)-\mathrm{C}(4)$ & $117.2(4)$ & $\mathrm{N}(2)-\mathrm{N}(1)-\mathrm{C}(11)-\mathrm{O}(2)$ & $-1.6(7)$ \\
$\mathrm{O}(2)-\mathrm{C}(11)$ & $1.238(5)$ & $\mathrm{O}(2)-\mathrm{C}(11)-\mathrm{N}(1)$ & $123.5(4)$ & $\mathrm{N}(2)-\mathrm{N}(1)-\mathrm{C}(11)-\mathrm{C}(10)$ & $176.9(4)$ \\
$\mathrm{O}(3)-\mathrm{C}(12)$ & $1.218(5)$ & $\mathrm{O}(3)-\mathrm{C}(12)-\mathrm{N}(2)$ & $124.2(4)$ & $\mathrm{O}(1)-\mathrm{C}(10)-\mathrm{C}(11)-\mathrm{O}(2)$ & $171.7(3)$ \\
$\mathrm{C}(12)-\mathrm{C}(13)$ & $1.531(6)$ & $\mathrm{N}(2)-\mathrm{C}(12)-\mathrm{C}(13)$ & $112.8(3)$ & $\mathrm{N}(1)-\mathrm{N}(2)-\mathrm{C}(12)-\mathrm{O}(3)$ & $5.8(7)$ \\
$\mathrm{C}(8)-\mathrm{C}(9)$ & $1.386(7)$ & $\mathrm{C}(14)-\mathrm{C}(13)-\mathrm{C}(12)$ & $109.3(5)$ & $\mathrm{N}(1)-\mathrm{N}(2)-\mathrm{C}(12)-\mathrm{C}(13)$ & $-175.2(4)$ \\
$\mathrm{C}(9)-\mathrm{C}(10)$ & $1.368(7)$ & $\mathrm{O}(3)-\mathrm{C}(12)-\mathrm{C}(13)$ & $123.0(4)$ & $\mathrm{O}(3)-\mathrm{C}(12)-\mathrm{C}(13)-\mathrm{C}(14)$ & $-70.8(6)$ \\
$\mathrm{C}(10)-\mathrm{C}(11)$ & $1.465(6)$ & $\mathrm{C}(6)-\mathrm{C}(1)-\mathrm{C}(2)$ & $122.5(4)$ & $\mathrm{N}(2)-\mathrm{C}(12)-\mathrm{C}(13)-\mathrm{C}(14)$ & $110.2(5)$ \\
$\mathrm{C}(4)-\mathrm{C}(7)$ & $1.455(6)$ & $\mathrm{O}(1)-\mathrm{C}(7)-\mathrm{C}(8)$ & $109.1(4)$ & $\mathrm{C}(10)-\mathrm{O}(1)-\mathrm{C}(7)-\mathrm{C}(4)$ & $177.6(3)$ \\
\hline
\end{tabular}

In the crystal structure, $\mathrm{C}(1), \mathrm{C}(2), \mathrm{C}(3), \mathrm{C}(4), \mathrm{C}(5)$, and $\mathrm{C}(6)$ formed a plane with a mean deviation of $0.0153 \AA$, defined as plane $\mathrm{I} ; \mathrm{C}(7), \mathrm{C}(8), \mathrm{C}(9), \mathrm{C}(10)$, and $\mathrm{O}(1)$ formed a plane with a mean deviation of $0.0150 \AA$, defined as plane II; $\mathrm{O}(2), \mathrm{C}(11), \mathrm{N}(1)$, and $\mathrm{N}(2)$ formed a plane with a mean deviation of $0.0047 \AA$, defined as plane III; O(3), C(12), C(13), and C(14) were not coplanar, which were defined factitiously as plane IV with a mean deviation of $0.3708 \AA$ (Figure 1 and Table 3). Planes II, III, IV formed a dihedral angle with plane I of $10.0^{\circ}, 12.4^{\circ}$, and $56.9^{\circ}$. Planes III and IV formed a dihedral angle with plane II of $6.8^{\circ}$ and $47.7^{\circ}$, and the dihedral angle between planes III and IV was $50.6^{\circ}$. The related data is summarized in Table 3.

Table 3. The dihedral angles and the mean deviation of the planes in compound III-3-2.

\begin{tabular}{cccc}
\hline Different planes & Dihedral angles $\left(^{\circ}\right)$ & Defination of the planes & $\begin{array}{c}\text { The mean deviation of } \\
\text { the plane }(\mathbf{\AA})\end{array}$ \\
\hline Plane I and plane II & 10.0 & Plane I (C1 to C6) & 0.0153 \\
Plane I and plane III & 12.4 & Plane II (C7 to C10, O1) & 0.0150 \\
Plane I and plane IV & 56.9 & Plane III (O2, C11, N1, N2) & 0.0047 \\
Plane II and plane III & 6.8 & Plane IV (O3, C12, C13, C14) & 0.3708 \\
Plane II and plane IV & 47.7 & & \\
Plane III and plane IV & 50.6 & & \\
\hline
\end{tabular}

\subsection{Bioassay}

\subsubsection{Insecticidal Activity}

Considering that our previous aromatic diacylhydrazide compounds displayed good insecticidal activities against dipterous and lepidopterous insects, Plutella xylostella, Mythimna separata, and Culex pipiens pallens were chosen to evaluate whether the aliphatic compounds retained the insecticidal activity. The results in Table 4 show that compounds III had moderate to poor insecticidal properties. The best one was compound III-8-1, with activities of $60 \%, 50 \%$, and $60 \%$ against P. xylostella, M. separata, and C. pipiens pallens at 200,200 , and $10 \mathrm{mg} \cdot \mathrm{L}^{-1}$, respectively. Comparison of the activity between the title compounds and the aromatic diacylhydrazide compound 
IV-1 from our previous study [16-22] revealed that the replacement of the rigid aromatic rings (IV) by the flexible aliphatic chains (III) had a negative effect on the insecticidal activity.

Table 4. Larvicidal activity of title compounds III.

\begin{tabular}{|c|c|c|c|c|c|}
\hline Compd. & $\mathbf{R}^{1}$ & $\mathbf{R}^{2}$ & $\begin{array}{l}\text { Plutella xylostella } \\
\text { Larvicidal activity } \\
(\%) \text { at } 200 \mathrm{mg} \cdot \mathbf{L}^{-1}\end{array}$ & $\begin{array}{l}\text { Mythimna separata } \\
\text { Larvicidal activity } \\
(\%) \text { at } 200 \cdot \mathrm{mg} \mathrm{L}^{-1}\end{array}$ & $\begin{array}{c}\text { Culex pipiens pallens } \\
\text { Larvicidal activity } \\
(\%) \text { at } 10 \mathrm{mg} \cdot \mathrm{L}^{-1}\end{array}$ \\
\hline III-3-1 & $\mathrm{CH}_{3}$ & $4-\mathrm{Cl}$ & 45 & 30 & 20 \\
\hline III-3-2 & $\mathrm{CH}_{2} \mathrm{CH}_{3}$ & $4-\mathrm{Cl}$ & 40 & 30 & 20 \\
\hline III-3-3 & $n-\mathrm{C}_{3} \mathrm{H}_{7}$ & 4-Cl & 55 & 40 & 30 \\
\hline III-3-4 & $i-\mathrm{C}_{3} \mathrm{H}_{7}$ & 4-Cl & 30 & 45 & 45 \\
\hline III-3-5 & $n-\mathrm{C}_{5} \mathrm{H}_{11}$ & $4-\mathrm{Cl}$ & 35 & 30 & 20 \\
\hline III-3-6 & $n-\mathrm{C}_{6} \mathrm{H}_{13}$ & $4-\mathrm{Cl}$ & 25 & 35 & 10 \\
\hline III-3-7 & $n-\mathrm{C}_{7} \mathrm{H}_{15}$ & $4-\mathrm{Cl}$ & 30 & 30 & 10 \\
\hline III-3-8 & $n-\mathrm{C}_{8} \mathrm{H}_{17}$ & $4-\mathrm{Cl}$ & 10 & 15 & 20 \\
\hline III-3-9 & $n-\mathrm{C}_{9} \mathrm{H}_{19}$ & $4-\mathrm{Cl}$ & 15 & 10 & 30 \\
\hline III-1-1 & $\mathrm{CH}_{3}$ & $2-\mathrm{Cl}$ & 45 & 35 & 40 \\
\hline III-2-1 & $\mathrm{CH}_{3}$ & $3-\mathrm{Cl}$ & 20 & 20 & 10 \\
\hline III-4-1 & $\mathrm{CH}_{3}$ & $2-F$ & 35 & 30 & 45 \\
\hline III-5-1 & $\mathrm{CH}_{3}$ & $3-F$ & 10 & 10 & 20 \\
\hline III-6-1 & $\mathrm{CH}_{3}$ & $4-F$ & 35 & 30 & 40 \\
\hline III-7-1 & $\mathrm{CH}_{3}$ & 2,4-di-F & 40 & 30 & 30 \\
\hline III-8-1 & $\mathrm{CH}_{3}$ & 2,6-di-F & 60 & 50 & 60 \\
\hline III-9-1 & $\mathrm{CH}_{3}$ & $2-\mathrm{NO}_{2}$ & 25 & 20 & 30 \\
\hline III-10-1 & $\mathrm{CH}_{3}$ & $3-\mathrm{NO}_{2}$ & 35 & 10 & 20 \\
\hline III-11-1 & $\mathrm{CH}_{3}$ & $4-\mathrm{NO}_{2}$ & 20 & 30 & 20 \\
\hline III-12-1 & $\mathrm{CH}_{3}$ & $\mathrm{H}$ & 10 & 35 & 35 \\
\hline III-13-1 & $\mathrm{CH}_{3}$ & $4-\mathrm{CH}_{3}$ & 35 & 30 & 25 \\
\hline III-14-1 & $\mathrm{CH}_{3}$ & $4-\mathrm{OCH}_{3}$ & 30 & 25 & 20 \\
\hline III-15-1 & $\mathrm{CH}_{3}$ & $4-\mathrm{Br}$ & 10 & 20 & 25 \\
\hline IV-1 & $4-\mathrm{CH}_{3}$ & $4-\mathrm{Cl}$ & 88 & 85 & 90 \\
\hline RH-5849 & & & 100 & 100 & 100 \\
\hline
\end{tabular}

\subsubsection{Fungicidal Activity}

The in vivo anti-fungal activities of the title compounds against Fusarium oxysporum, Corynespora cassiicola, Botrytis cinerea, and Rhizoctonia solanii are listed in Table 5. Most of the title compounds showed moderate to good activity against $B$. cinerea and $R$. solanii at $500 \mu \mathrm{g} \cdot \mathrm{mL}^{-1}$ in vivo. For instance, the inhibitory rates of III-11-1 and III-3-1 against $B$. cinerea were $92.52 \% \pm 2.71 \%$ and $84.23 \% \pm 2.43 \%$, which was equal to the positive control $40 \%$ pyrimethanil SC $(89.57 \% \pm 2.15 \%)$. The inhibitory rates of III-3-1 and III-9-1 against $R$. solanii were $93.43 \% \pm 1.63 \%$ and $88.62 \% \pm 1.62 \%$, which was the same as the control level of $3 \%$ validamycin AS $(92.21 \% \pm 2.41 \%)$. The aliphatic chain length showed significant effects on the fungicidal activities against $B$. cinerea and $R$. solanii. In general, the shorter the chain, the better the corresponding activity was. The structure and position of $\mathrm{R}^{2}$ also affected the fungicidal activity against $R$. solanii. When $\mathrm{R}^{2}$ 
was $\mathrm{NO}_{2}$ and $\mathrm{Cl}$ at the ortho or para position, such as in III-3-1, III-1-1, III-9-1, and III-11-1, a higher fungicidal activity was observed. The results showed that meta substitution on the phenyl ring decreased the activity, and the electron-donating groups at the para position significantly decreased the activity. All the compounds showed moderate to poor activity against $F$. oxysporum and C. cassiicola. Compared with aromatic diacylhydrazide IV-1, the aliphatic derivatives showed improved and increased fungicidal activity.

Table 5. Fungicidal activities of title compounds against four fungus species at $500 \mu \mathrm{g} \cdot \mathrm{mL}^{-1}$ in vivo.

\begin{tabular}{|c|c|c|c|c|c|c|}
\hline \multirow{2}{*}{ Compd. } & \multirow{2}{*}{$\mathbf{R}^{1}$} & \multirow{2}{*}{$\mathbf{R}^{2}$} & \multicolumn{4}{|c|}{ Control efficacy (\%) } \\
\hline & & & F. oxysporum & C. cassiicola & B. cinerea & R. solanii \\
\hline III-3-1 & $\mathrm{CH}_{3}$ & $4-\mathrm{Cl}$ & $33.41 \pm 1.22$ & $19.32 \pm 0.93$ & $84.23 \pm 2.43$ & $93.43 \pm 1.63$ \\
\hline III-3-2 & $\mathrm{CH}_{2} \mathrm{CH}_{3}$ & $4-\mathrm{Cl}$ & $34.23 \pm 0.84$ & $32.43 \pm 1.23$ & $61.23 \pm 0.51$ & $62.42 \pm 1.61$ \\
\hline III-3-3 & $n-\mathrm{C}_{3} \mathrm{H}_{7}$ & $4-\mathrm{Cl}$ & $16.32 \pm 1.12$ & $41.32 \pm 1.31$ & $52.34 \pm 1.23$ & $51.32 \pm 1.52$ \\
\hline III-3-4 & $i-\mathrm{C}_{3} \mathrm{H}_{7}$ & $4-\mathrm{Cl}$ & $15.76 \pm 0.42$ & $36.43 \pm 1.49$ & $55.13 \pm 1.02$ & $48.32 \pm 0.81$ \\
\hline III-3-5 & $n-\mathrm{C}_{5} \mathrm{H}_{11}$ & 4-Cl & $9.32 \pm 0.65$ & $12.43 \pm 0.91$ & $11.35 \pm 0.80$ & $43.32 \pm 1.41$ \\
\hline III-3-6 & $n-\mathrm{C}_{6} \mathrm{H}_{13}$ & $4-\mathrm{Cl}$ & $33.62 \pm 1.03$ & $28.23 \pm 0.54$ & $27.53 \pm 1.43$ & $52.32 \pm 0.97$ \\
\hline III-3-7 & $n-\mathrm{C}_{7} \mathrm{H}_{15}$ & $4-\mathrm{Cl}$ & $11.42 \pm 0.52$ & $12.61 \pm 0.61$ & $25.12 \pm 0.91$ & $32.21 \pm 0.72$ \\
\hline III-3-8 & $n-\mathrm{C}_{8} \mathrm{H}_{17}$ & $4-\mathrm{Cl}$ & $21.34 \pm 0.53$ & $22.34 \pm 0.72$ & $30.52 \pm 0.79$ & $44.62 \pm 0.72$ \\
\hline III-3-9 & $n-\mathrm{C}_{9} \mathrm{H}_{19}$ & $4-\mathrm{Cl}$ & $19.43 \pm 0.63$ & $12.33 \pm 0.59$ & $32.39 \pm 0.53$ & $52.52 \pm 1.02$ \\
\hline III-1-1 & $\mathrm{CH}_{3}$ & $2-\mathrm{Cl}$ & $35.85 \pm 0.55$ & $28.24 \pm 2.00$ & $82.38 \pm 3.02$ & $84.13 \pm 1.16$ \\
\hline III-2-1 & $\mathrm{CH}_{3}$ & $3-\mathrm{Cl}$ & $25.73 \pm 1.35$ & $38.62 \pm 1.45$ & $33.54 \pm 2.12$ & $48.63 \pm 1.63$ \\
\hline III-4-1 & $\mathrm{CH}_{3}$ & $2-\mathrm{F}$ & $18.61 \pm 0.62$ & $12.63 \pm 1.27$ & $62.36 \pm 1.72$ & $65.62 \pm 1.82$ \\
\hline III-5-1 & $\mathrm{CH}_{3}$ & $3-\mathrm{F}$ & $9.32 \pm 0.24$ & $13.72 \pm 0.85$ & $35.43 \pm 1.53$ & $25.53 \pm 1.63$ \\
\hline III-6-1 & $\mathrm{CH}_{3}$ & $4-\mathrm{F}$ & $18.52 \pm 1.34$ & $34.43 \pm 1.62$ & $48.45 \pm 2.04$ & $54.56 \pm 1.23$ \\
\hline III-7-1 & $\mathrm{CH}_{3}$ & 2,4-di-F & $9.53 \pm 0.53$ & $23.83 \pm 1.11$ & $63.32 \pm 2.21$ & $51.42 \pm 1.51$ \\
\hline III-8-1 & $\mathrm{CH}_{3}$ & 2,6-di-F & $13.21 \pm 2.12$ & $23.22 \pm 1.42$ & $36.13 \pm 1.23$ & $26.32 \pm 1.26$ \\
\hline III-9-1 & $\mathrm{CH}_{3}$ & $2-\mathrm{NO}_{2}$ & $62.34 \pm 1.41$ & $51.52 \pm 2.34$ & $82.62 \pm 2.21$ & $88.62 \pm 1.62$ \\
\hline III-10-1 & $\mathrm{CH}_{3}$ & $3-\mathrm{NO}_{2}$ & $47.34 \pm 1.03$ & $43.53 \pm 1.34$ & $37.43 \pm 1.62$ & $36.62 \pm 1.63$ \\
\hline III-11-1 & $\mathrm{CH}_{3}$ & $4-\mathrm{NO}_{2}$ & $34.62 \pm 1.23$ & $32.53 \pm 1.72$ & $92.52 \pm 2.71$ & $38.43 \pm 0.53$ \\
\hline III-12-1 & $\mathrm{CH}_{3}$ & $\mathrm{H}$ & $32.61 \pm 1.34$ & $63.72 \pm 1.23$ & $66.62 \pm 2.52$ & $39.53 \pm 2.32$ \\
\hline III-13-1 & $\mathrm{CH}_{3}$ & $4-\mathrm{CH}_{3}$ & $12.82 \pm 1.01$ & $35.33 \pm 1.73$ & $27.63 \pm 1.73$ & $49.34 \pm 1.35$ \\
\hline III-14-1 & $\mathrm{CH}_{3}$ & $4-\mathrm{OCH}_{3}$ & $31.72 \pm 1.72$ & $28.92 \pm 1.45$ & $12.42 \pm 1.43$ & $52.54 \pm 2.62$ \\
\hline III-15-1 & $\mathrm{CH}_{3}$ & $4-\mathrm{Br}$ & $40.42 \pm 2.51$ & $18.62 \pm 0.82$ & $32.23 \pm 0.66$ & $23.72 \pm 1.32$ \\
\hline IV-1 & $4-\mathrm{CH}_{3}$ & 4-Cl & $19.78 \pm 0.84$ & $48.56 \pm 1.21$ & $21.45 \pm 0.97$ & $20.78 \pm 1.06$ \\
\hline $\begin{array}{c}\text { Acetone } \\
\text { (blank control) }\end{array}$ & & & $1.92 \pm 0.82$ & $2.25 \pm 0.72$ & $1.83 \pm 0.53$ & $2.62 \pm 0.84$ \\
\hline Fungicides \# & & & $94.17 \pm 1.80^{\mathrm{a}}$ & $95.21 \pm 1.94^{b}$ & $89.57 \pm 2.15^{c}$ & $92.21 \pm 2.41^{\mathrm{d}}$ \\
\hline
\end{tabular}

\subsubsection{Anti-Tumor Activity}

The in vitro anti-tumor activity of the title compounds against four cancer cell lines is listed in Table 6. Most of the title compounds showed inhibition activity against the tested cancer cell lines. The activity of III-3-1 $\left(\mathrm{IC}_{50}=21.6 \mu \mathrm{M}\right)$, III-1-1 $\left(\mathrm{IC}_{50}=25.3 \mu \mathrm{M}\right)$ and III-8-1 $\left(\mathrm{IC}_{50}=25.9 \mu \mathrm{M}\right)$ was 
better than that of doxorubicin $\left(\mathrm{IC}_{50}=35.6 \mu \mathrm{M}\right)$ against human promyelocytic leukemic cells (HL-60). The activity of III-3-2 $\left(\mathrm{IC}_{50}=35.8 \mu \mathrm{M}\right)$ was similar to that of doxorubicin $\left(\mathrm{IC}_{50}=35.6 \mu \mathrm{M}\right)$ against HL-60. III-8-1 exhibited good inhibition activity against solid human gastric carcinoma cells (BGC-823), with an activity $\left(\mathrm{IC}_{50}=10.8 \mu \mathrm{M}\right)$ that was close to that of doxorubicin $\left(\mathrm{IC}_{50}=10.2 \mu \mathrm{M}\right)$. III-3-1 and III-8-1 also had good activity $\left(\mathrm{IC}_{50}=15.2\right.$ and $\left.18.9 \mu \mathrm{M}\right)$ against human hepatocellular carcinoma cells (Bel-7402). However, the activity of title compounds against human nasopharyngeal carcinoma cells (KB) was poor.

The preliminary structure-activity relationship showed that the aliphatic chain length had a significant impact on the anti-tumor activity against HL-60. Generally, the shorter the chain, the better the corresponding activity was. The structure and position of $\mathrm{R}^{2}$ also affected the anti-tumor activity against HL-60. When $\mathrm{R}^{2}$ was $\mathrm{Cl}$ and $\mathrm{F}$ at the ortho or para position, such as in III-3-1, III-1-1, and III-8-1, a higher anti-tumor activity was observed. The anti-tumor activity of the title compounds was much better than that of the aromatic diacylhydrazides.

Table 6. Anti-tumor activity of title compounds III.

\begin{tabular}{|c|c|c|c|c|c|c|}
\hline \multirow{2}{*}{ Compd. } & \multirow{2}{*}{$\mathbf{R}^{1}$} & \multirow{2}{*}{$\mathbf{R}^{2}$} & \multicolumn{4}{|c|}{$\mathrm{IC}_{50}$ values $(\mu \mathrm{M})$} \\
\hline & & & HL-60 & BGC-823 & Bel-7402 & KB \\
\hline III-3-1 & $\mathrm{CH}_{3}$ & $4-\mathrm{Cl}$ & 21.6 & 32.5 & 15.2 & 38.5 \\
\hline III-3-2 & $\mathrm{CH}_{2} \mathrm{CH}_{3}$ & $4-\mathrm{Cl}$ & 35.8 & 25.9 & 56.7 & 32.1 \\
\hline III-3-3 & $n-\mathrm{C}_{3} \mathrm{H}_{7}$ & $4-\mathrm{Cl}$ & 42.5 & 125.8 & 89.7 & 56.7 \\
\hline III-3-4 & $i-\mathrm{C}_{3} \mathrm{H}_{7}$ & $4-\mathrm{Cl}$ & 45.8 & 56.8 & 56.9 & 198.4 \\
\hline III-3-5 & $n-\mathrm{C}_{5} \mathrm{H}_{11}$ & $4-\mathrm{Cl}$ & 56.8 & 78.9 & 128.2 & 56.9 \\
\hline III-3-6 & $n-\mathrm{C}_{6} \mathrm{H}_{13}$ & $4-\mathrm{Cl}$ & 65.4 & 198.4 & 98.7 & 95.7 \\
\hline III-3-7 & $n-\mathrm{C}_{7} \mathrm{H}_{15}$ & $4-\mathrm{Cl}$ & 156.2 & 268.1 & 56.9 & 346.7 \\
\hline III-3-8 & $n-\mathrm{C}_{8} \mathrm{H}_{17}$ & $4-\mathrm{Cl}$ & 286.5 & 96.8 & 389.8 & 156.8 \\
\hline III-3-9 & $n-\mathrm{C}_{9} \mathrm{H}_{19}$ & $4-\mathrm{Cl}$ & 483.5 & 185.3 & 149.8 & 81.5 \\
\hline III-1-1 & $\mathrm{CH}_{3}$ & $2-\mathrm{Cl}$ & 25.3 & 29.4 & 28.7 & 59.7 \\
\hline III-2-1 & $\mathrm{CH}_{3}$ & $3-\mathrm{Cl}$ & 56.8 & 189.5 & 56.8 & 125.4 \\
\hline III-4-1 & $\mathrm{CH}_{3}$ & $2-\mathrm{F}$ & 59.4 & 48.2 & 45.1 & 198.7 \\
\hline III-5-1 & $\mathrm{CH}_{3}$ & $3-\mathrm{F}$ & 254.3 & 156.2 & 45.9 & 65.4 \\
\hline III-6-1 & $\mathrm{CH}_{3}$ & $4-\mathrm{F}$ & 52.4 & 23.5 & 59.7 & 89.4 \\
\hline III-7-1 & $\mathrm{CH}_{3}$ & 2,4-di-F & 53.6 & 45.2 & 49.2 & 98.4 \\
\hline III-8-1 & $\mathrm{CH}_{3}$ & 2,6-di-F & 25.9 & 10.8 & 18.9 & 29.7 \\
\hline III-9-1 & $\mathrm{CH}_{3}$ & $2-\mathrm{NO}_{2}$ & 59.3 & 56.8 & 158.2 & 286.4 \\
\hline III-10-1 & $\mathrm{CH}_{3}$ & $3-\mathrm{NO}_{2}$ & 159.5 & 256.4 & 98.7 & 45.8 \\
\hline III-11-1 & $\mathrm{CH}_{3}$ & $4-\mathrm{NO}_{2}$ & 102.3 & 152.1 & 94.1 & 56.4 \\
\hline III-12-1 & $\mathrm{CH}_{3}$ & $\mathrm{H}$ & 56.8 & 98.5 & 59.2 & 184.6 \\
\hline III-13-1 & $\mathrm{CH}_{3}$ & $4-\mathrm{CH}_{3}$ & 63.1 & 98.4 & 65.1 & 187.5 \\
\hline III-14-1 & $\mathrm{CH}_{3}$ & $4-\mathrm{OCH}_{3}$ & 45.5 & 158.4 & 108.9 & 204.2 \\
\hline III-15-1 & $\mathrm{CH}_{3}$ & $4-\mathrm{Br}$ & 526.7 & 254.2 & 125.9 & 253.4 \\
\hline IV-1 & $4-\mathrm{CH}_{3}$ & $4-\mathrm{Cl}$ & 598.7 & 421.8 & 261.5 & 398.7 \\
\hline doxorubicin & & & 35.6 & 10.2 & 9.7 & 15.8 \\
\hline
\end{tabular}




\section{Experimental Section}

\subsection{General Information}

Melting points were determined with a Cole-Parmer melting point apparatus (Cole-Parmer, Vernon Hills, IL, USA) (thermometer was uncorrected). IR spectra were recorded on a NEXUS-470 FTIR spectrometer (International Equipment Trading Ltd., Vernon Hills, IL, USA) with KBr pellets. ${ }^{1} \mathrm{H}$ NMR spectra were recorded with a Bruker DPX300 instrument (Bruker, Billerica, MA, USA) and tetramethylsilane was used as an internal standard. Analytical thin-layer chromatography (TLC) was carried out on precoated plates (silica gel 60 F254) and spots were visualized under ultraviolet light. Elemental analyses (C, H and N) were carried out with a Flash EA 1112 elemental analyzer (Thermo Finnigan, Bremen, Germany). Mass spectra were measured on a Bruker ESQUIRE-LC spectrometer (Bruker, Fallanden, Switzerland). The X-ray crystal diffraction (Bruker, Fallanden, Switzerland) data were collected with a Rigaku Saturn diffractometer at 294(2) K and the crystal structures were calculated using the SHELXL program package and refined by full-matrix least squares procedures at Nankai University (Tianjin, China).

\subsection{Synthetic Procedures}

\subsubsection{General Synthetic Procedure for the Key Intermediates}

Preparation of different 5-substituted phenyl-2-furoic acid I was performed according to the method described in references [16-22] and the 5-substituted phenyl-2-furoyl hydrazides II was performed as previously described [16-23].

\subsubsection{General Synthetic Procedure for the Title Compounds III}

A mixture of aliphatic acid $(0.05 \mathrm{~mol})$ and thionyl chloride $(0.15 \mathrm{~mol})$ was refluxed in anhydrous benzene for $3 \mathrm{~h}$. The excess thionyl chloride and the solvent were distilled off and the residue was dissolved in anhydrous dichloromethane. The resultant solution was added to 5-substituted phenyl-2-furoyl hydrazides II. The mixture was stirred and refluxed for $5 \mathrm{~h}$. After cooling, the solid was filtered and recrystallized from ethyl acetate to obtain the title compounds. All the title compounds were solid. Their structures were confirmed by ${ }^{1} \mathrm{H}$ NMR, IR, MS, and elemental analysis.

$\boldsymbol{N}$-Acetyl- $\boldsymbol{N}^{\prime}$-[5-(2'-cholorophenyl)-2-furoyl]hydrazine (III-1-1). White solid: yield 79.4\%, m.p. 152-153 ${ }^{\circ} \mathrm{C}$. IR (KBr) $v_{\max }: 3416.8$, 3223.2, 2987.5, 1641.5, 1534.2, 1473.3, 1265.7, 1185.1, $1034.7 \mathrm{~cm}^{-1} .{ }^{1} \mathrm{H}$ NMR (300 MHz, DMSO-d $) \delta: 2.16\left(\mathrm{~s}, 3 \mathrm{H}, \mathrm{CH}_{3}\right), 7.33(\mathrm{~d}, J=3.69 \mathrm{~Hz}, 1 \mathrm{H}, \mathrm{FuH})$, 7.39 (d, $J=3.69 \mathrm{~Hz}, 1 \mathrm{H}, \mathrm{FuH}), 7.41-7.54$ (m, 2H, 2ArH-Fu), 7.61-7.64 (m, 1H, ArH-Fu), 8.23 (m, 1H, $\mathrm{ArH}-\mathrm{Fu}), 10.43(\mathrm{~s}, 1 \mathrm{H}, \mathrm{NH}), 10.61(\mathrm{~s}, 1 \mathrm{H}, \mathrm{NH})$. MS/ESI: $m / e(\%) 301.1[\mathrm{M}+\mathrm{Na}]^{+}$. Anal. Calcd. (\%) for $\mathrm{C}_{13} \mathrm{H}_{11} \mathrm{ClN}_{2} \mathrm{O}_{3}$ : C, 56.03; H, 3.98; N, 10.05. Found: C, 56.22; H, 3.81; N, 10.20.

$\boldsymbol{N}$-Acetyl- $\boldsymbol{N}^{\prime}$-[5-(3'-cholorophenyl)-2-furoyl]hydrazine (III-2-1). White solid: yield 73.6\%, m.p. $136-137{ }^{\circ} \mathrm{C}$. IR (KBr) $v_{\max }: 3412.5,3243.1,3023.3,1642.2,1524.1,1462.4,1327.2,1263.3$, 1182.4, $1063.1 \mathrm{~cm}^{-1} .{ }^{1} \mathrm{H}$ NMR $\left(300 \mathrm{MHz}, \mathrm{DMSO}-d_{6}\right) \delta: 2.16\left(\mathrm{~s}, 3 \mathrm{H}, \mathrm{CH}_{3}\right), 7.30(\mathrm{~d}, J=3.63 \mathrm{~Hz}, 1 \mathrm{H}$, $\mathrm{FuH}), 7.34(\mathrm{~d}, J=3.63 \mathrm{~Hz}, 1 \mathrm{H}, \mathrm{FuH}), 7.47-7.52$ (m, 2H, ArH-Fu), 7.93-7.96 (m, 1H, ArH-Fu), 
8.15 (m, 1H, ArH-Fu), 10.46 (s, 1H, NH), 10.76 (s, 1H, NH). MS/ESI: m/e (\%) $279.1[\mathrm{M}+\mathrm{H}]^{+}$. Anal. Calcd. (\%) for $\mathrm{C}_{13} \mathrm{H}_{11} \mathrm{ClN}_{2} \mathrm{O}_{3}$ : C, 56.03; H, 3.98; N, 10.05. Found: C, 55.89; H, 4.18; N, 9.87.

$\boldsymbol{N}$-Acetyl- $\boldsymbol{N}^{\prime}$-[5-(4'-cholorophenyl)-2-furoyl]hydrazine (III-3-1). White solid: yield 79.2\%, m.p. $135-136{ }^{\circ} \mathrm{C}$. IR (KBr) $v_{\max }: 3412.5$, 3232.6, 3094.4, 1621.5, 1574.5, 1483.6, 1384.1, 1286.7, $1192.1,1082.7 \mathrm{~cm}^{-1} .{ }^{1} \mathrm{H}$ NMR $\left(300 \mathrm{MHz}, \mathrm{DMSO}-d_{6}\right) \delta: 2.16\left(\mathrm{~s}, 3 \mathrm{H}, \mathrm{CH}_{3}\right), 7.33(\mathrm{~d}, J=3.69 \mathrm{~Hz}, 1 \mathrm{H}$, $\mathrm{FuH}), 7.39$ (d, $J=3.69 \mathrm{~Hz}, 1 \mathrm{H}, \mathrm{FuH}), 7.41-7.54(\mathrm{~m}, 2 \mathrm{H}, 2 \mathrm{ArH}-\mathrm{Fu}), 7.61-7.64(\mathrm{~m}, 1 \mathrm{H}, \mathrm{ArH}-\mathrm{Fu})$, 8.21-8.24 (m, 1H, ArH-Fu), 10.61 (s, 1H, NH), 10.66 (s, 1H, NH). MS/ESI: m/e (\%) $279.2[\mathrm{M}+\mathrm{H}]^{+}$. Anal. Calcd. (\%) for $\mathrm{C}_{13} \mathrm{H}_{11} \mathrm{ClN}_{2} \mathrm{O}_{3}: \mathrm{C}, 56.03 ; \mathrm{H}, 3.98 ; \mathrm{N}, 10.05$. Found: C, 56.26; H, 4.07; N, 9.94.

$\boldsymbol{N}$-Acetyl- $\boldsymbol{N}^{\prime}$-[5-(2'-fluorophenyl)-2-furoyl]hydrazine (III-4-1). White solid: yield 74.6\%, m.p. $150-151{ }^{\circ} \mathrm{C}$. IR (KBr) $v_{\max }: 3415.2$, 3263.1, 2994.8, 1643.8, 1523.5, 1452.6, 1323.1, 1261.7, 1153.1, 1123.6, $1093.4 \mathrm{~cm}^{-1} .{ }^{1} \mathrm{H}$ NMR $\left(300 \mathrm{MHz}, \mathrm{DMSO}-d_{6}\right) \delta: 2.16\left(\mathrm{~s}, 3 \mathrm{H}, \mathrm{CH}_{3}\right), 6.97(\mathrm{~d}, J=3.66 \mathrm{~Hz}$, $1 \mathrm{H}, \mathrm{FuH}), 7.41$ (d, $J=3.69 \mathrm{~Hz}, 1 \mathrm{H}, \mathrm{FuH}), 7.69$ (td, $J=7.77,1.38 \mathrm{~Hz}, 1 \mathrm{H}, \mathrm{ArH}-\mathrm{Fu}), 7.83$ (td, $J=7.67$, $1.22 \mathrm{~Hz}, 1 \mathrm{H}, \mathrm{ArH}-\mathrm{Fu}), 8.00-8.05$ (m, 2H, ArH-Fu), 10.44 (s, 1H, NH), 10.68 (s, 1H, NH). MS/ESI: m/e (\%) $262.9[\mathrm{M}+\mathrm{H}]^{+}$. Anal. Calcd. (\%) for $\mathrm{C}_{13} \mathrm{H}_{11} \mathrm{FN}_{2} \mathrm{O}_{3}: \mathrm{C}, 59.54 ; \mathrm{H}, 4.23 ; \mathrm{N}, 10.68$. Found: C, $59.63 ; \mathrm{H}, 4.01 ; \mathrm{N}, 10.83$.

$\boldsymbol{N}$-Acetyl- $\boldsymbol{N}^{\prime}$-[5-(3'-fluorophenyl)-2-furoyl]hydrazine (III-5-1). White solid: yield 69.5\%, m.p. 143-144 ${ }^{\circ} \mathrm{C}$. IR (KBr) $v_{\max }$ : 3398.9, 3123.6, 2978.1, 1653.5, 1583.5, 1455.6, 1354.5, 1233.4, 1154.1, $1083.5 \mathrm{~cm}^{-1} .{ }^{1} \mathrm{H}$ NMR $\left(300 \mathrm{MHz}, \mathrm{DMSO}-d_{6}\right) \delta: 2.16\left(\mathrm{~s}, 3 \mathrm{H}, \mathrm{CH}_{3}\right), 7.38(\mathrm{~d}, J=3.66 \mathrm{~Hz}, 1 \mathrm{H}$, $\mathrm{FuH}), 7.47(\mathrm{~d}, J=3.66 \mathrm{~Hz}, 1 \mathrm{H}, \mathrm{FuH}), 7.80-7.83(\mathrm{~m}, 1 \mathrm{H}, \mathrm{ArH}-\mathrm{Fu}), 8.21-8.25(\mathrm{~m}, 1 \mathrm{H}, \mathrm{ArH}-\mathrm{Fu})$, 8.39-8.42 (m, 1H, ArH-Fu), 8.83-8.86 (m, 1H, ArH-Fu), 10.65 (s, 1H, NH), 10.80 (s, 1H, NH). MS/ESI: $m / e(\%) 285.1[\mathrm{M}+\mathrm{Na}]^{+}$. Anal. Calcd. (\%) for $\mathrm{C}_{13} \mathrm{H}_{11} \mathrm{FN}_{2} \mathrm{O}_{3}: \mathrm{C}, 59.54 ; \mathrm{H}, 4.23 ; \mathrm{N}, 10.68$. Found: C, 59.71; H, 4.48; N, 10.75 .

$\boldsymbol{N}$-Acetyl- $\boldsymbol{N}^{\prime}$-[5-(4'-fluorophenyl)-2-furoyl]hydrazine (III-6-1). White solid: yield 80.1\%, m.p. 161-162 ${ }^{\circ} \mathrm{C}$. IR (KBr) $v_{\max }$ : 3404.2, 3232.3, 2883.4, 1643.5, 1546.3, 1463.2, 1362.1, 1223.3, $1153.8,1062.1 \mathrm{~cm}^{-1} .{ }^{1} \mathrm{H}$ NMR $\left(300 \mathrm{MHz}, \mathrm{DMSO}-d_{6}\right) \delta: 2.16\left(\mathrm{~s}, 3 \mathrm{H}, \mathrm{CH}_{3}\right), 7.41(\mathrm{~d}, J=3.69 \mathrm{~Hz}, 1 \mathrm{H}$, $\mathrm{FuH}), 7.50$ (d, $J=3.66 \mathrm{~Hz}, 1 \mathrm{H}, \mathrm{FuH}), 8.24$ (d, $J=7.05 \mathrm{~Hz}, 2 \mathrm{H}, \mathrm{ArH}-\mathrm{Fu}), 8.33-8.38$ (m, 2H, ArH-Fu), $10.67(\mathrm{~s}, 1 \mathrm{H}, \mathrm{NH}), 10.77(\mathrm{~s}, 1 \mathrm{H}, \mathrm{NH})$. MS/ESI: m/e (\%) $263.1[\mathrm{M}+\mathrm{H}]^{+}$. Anal. Calcd. (\%) for $\mathrm{C}_{13} \mathrm{H}_{11} \mathrm{FN}_{2} \mathrm{O}_{3}$ : C, 59.54; H, 4.23; N, 10.68. Found: C, 59.36; H, 3.99; N, 10.43.

$\boldsymbol{N}$-Acetyl- $\boldsymbol{N}^{\prime}$-[5-(2',4'-difluorophenyl)-2-furoyl]hydrazine (III-7-1). White solid: yield 79.2\%, m.p. $152-153{ }^{\circ} \mathrm{C}$. IR (KBr) $v_{\max }: 3434.5$, 3223.6, 3053.3, 1653.2, 1554.3, 1443.3, 1353.1, 1223.7, $1034.2 \mathrm{~cm}^{-1} .{ }^{1} \mathrm{H}$ NMR (300 MHz, DMSO- $\left.d_{6}\right) \delta: 2.16\left(\mathrm{~s}, 3 \mathrm{H}, \mathrm{CH}_{3}\right), 7.02(\mathrm{t}, J=3.71 \mathrm{~Hz}, 1 \mathrm{H}, \mathrm{FuH})$, 7.35-7.49 (m, 4H, 1FuH + 3ArH-Fu), 8.19-8.25 (m,1H,ArH-Fu), 10.65 (s, 1H, NH), $10.68(\mathrm{~s}, 1 \mathrm{H}$, $\mathrm{NH})$. MS/ESI: $m / e(\%) 281.2[\mathrm{M}+\mathrm{H}]^{+}$. Anal. Calcd. (\%) for $\mathrm{C}_{13} \mathrm{H}_{10} \mathrm{~F}_{2} \mathrm{~N}_{2} \mathrm{O}_{3}: \mathrm{C}, 55.72 ; \mathrm{H}, 3.60 ; \mathrm{N}$, 10.00. Found: C, 55.57; H, 3.68; N, 10.26.

$\boldsymbol{N}$-acetyl- $\boldsymbol{N}^{\prime}$-[5-(2',6'-difluorophenyl)-2-furoyl]hydrazine (III-8-1). White solid: yield 79.8\%, m.p. 139-140 ${ }^{\circ} \mathrm{C}$. IR (KBr) $v_{\max }$ : 3411.8, 3072.4, 1643.5, 1565.4, 1472.6, 1332.1, 1262.3, 1171.9, $1033.5 \mathrm{~cm}^{-1}$. ${ }^{1} \mathrm{H}$ NMR $\left(300 \mathrm{MHz}, \mathrm{DMSO}-d_{6}\right) \delta: 2.16\left(\mathrm{~s}, 3 \mathrm{H}, \mathrm{CH}_{3}\right), 7.23-7.29(\mathrm{~m}, 2 \mathrm{H}, \mathrm{FuH}+\mathrm{ArH}-\mathrm{Fu})$, $7.35(\mathrm{~d}, J=3.63 \mathrm{~Hz}, 1 \mathrm{H}, \mathrm{FuH}), 7.48-7.52$ (m, 1H, ArH-Fu), 7.81-7.84 (m, 1H, ArH-Fu), 7.91-7.94 
(m, 1H, ArH-Fu), 10.41 (s, 1H, NH), 10.59 (s, 1H, NH). MS/ESI: m/e (\%) $280.9[\mathrm{M}+\mathrm{H}]^{+}$. Anal. Calcd. (\%) for $\mathrm{C}_{13} \mathrm{H}_{10} \mathrm{~F}_{2} \mathrm{~N}_{2} \mathrm{O}_{3}$ : C, 55.72; H, 3.60; N, 10.00. Found: C, 55.98; H, 3.51; N, 9.87.

$\boldsymbol{N}$-Acetyl- $\boldsymbol{N}^{\prime}$-[5-(2'-nitrophenyl)-2-furoyl]hydrazine (III-9-1). Yellow solid: yield 82.3\%, m.p. $138-139{ }^{\circ} \mathrm{C}$. IR (KBr) $v_{\max }: 3417.4,3223.5,3063.1,1663.7,1553.4,1434.1,1273.7,1145.9$, $1073.4 \mathrm{~cm}^{-1} .{ }^{1} \mathrm{H}$ NMR (300 MHz, DMSO-d $) \delta: 2.16\left(\mathrm{~s}, 3 \mathrm{H}, \mathrm{CH}_{3}\right), 7.16(\mathrm{~d}, J=3.57 \mathrm{~Hz}, 1 \mathrm{H}, \mathrm{FuH})$, 7.33-7.39 (m, 3H, FuH + 2ArH-Fu), 8.05 (d, J=8.79 Hz, 2H, ArH-Fu), 10.43 (s, 1H, NH), 10.69 (s, 1H, NH). MS/ESI: m/e (\%) $312.2[\mathrm{M}+\mathrm{Na}]^{+}$. Anal. Calcd. (\%) for $\mathrm{C}_{13} \mathrm{H}_{11} \mathrm{~N}_{3} \mathrm{O}_{5}: \mathrm{C}, 53.98 ; \mathrm{H}, 3.83$; $\mathrm{N}, 14.53$. Found: C, 53.71; H, 4.00; N, 14.73.

$\boldsymbol{N}$-Acetyl- $\boldsymbol{N}^{\prime}$-[5-(3'-nitrophenyl)-2-furoyl]hydrazine (III-10-1). Yellow solid: yield 81.4\%, m.p. 143-144 ${ }^{\circ} \mathrm{C}$. IR (KBr) $v_{\max }$ : 3402.1, 3227.4, 2799.5 1634.1, 1562.3, 1454.5, 1345.3, 1273.7, $1164.4 \mathrm{~cm}^{-1} .{ }^{1} \mathrm{H}$ NMR (300 MHz, DMSO- $\left.d_{6}\right) \delta: 2.16\left(\mathrm{~s}, 3 \mathrm{H}, \mathrm{CH}_{3}\right), 6.99(\mathrm{t}, J=3.74 \mathrm{~Hz}, 1 \mathrm{H}, \mathrm{FuH})$, 7.29-7.38 (m, 2H, FuH + ArH-Fu), 7.45-7.53 (m, 1H, ArH-Fu), 8.24-8.32 (m, 1H, ArH-Fu), $10.66(\mathrm{~s}, 1 \mathrm{H}, \mathrm{NH}), 10.70(\mathrm{~s}, 1 \mathrm{H}, \mathrm{NH})$. MS/ESI: m/e (\%) $290.1[\mathrm{M}+\mathrm{H}]^{+}$. Anal. Calcd. (\%) for $\mathrm{C}_{13} \mathrm{H}_{11} \mathrm{~N}_{3} \mathrm{O}_{5}$ : C, 53.98; H, 3.83; N, 14.53. Found: C, 54.16; H, 3.65; N, 14.32.

$\boldsymbol{N}$-Acetyl- $\boldsymbol{N}^{\prime}$-[5-(4'-nitrophenyl)-2-furoyl]hydrazine (III-11-1). Yellow solid: yield 84.5\%, m.p. $140-141{ }^{\circ} \mathrm{C}$. IR (KBr) $v_{\max }: 3346.3,3023.4,1682.5,1543.7,1483.3,1334.8,1264.5,1145.4$, $1043.8 \mathrm{~cm}^{-1} .{ }^{1} \mathrm{H}$ NMR (300 MHz, DMSO- $\left.d_{6}\right) \delta: 2.16\left(\mathrm{~s}, 3 \mathrm{H}, \mathrm{CH}_{3}\right), 7.04-7.06(\mathrm{~m}, 1 \mathrm{H}, \mathrm{ArH}-\mathrm{Fu})$, 7.28-7.33 (m, 2H, FuH + ArH-Fu), 7.47 (d, $J=3.66 \mathrm{~Hz}, 1 \mathrm{H}, \mathrm{FuH}), 7.54-7.59$ (m, 1H, ArH-Fu), $10.52(\mathrm{~s}, 1 \mathrm{H}, \mathrm{NH}), 10.62(\mathrm{~s}, 1 \mathrm{H}, \mathrm{NH}) . \mathrm{MS} / \mathrm{ESI}: m / e(\%) 290.1[\mathrm{M}+\mathrm{H}]^{+}$. Anal. Calcd. (\%) for $\mathrm{C}_{13} \mathrm{H}_{11} \mathrm{~N}_{3} \mathrm{O}_{5}$ : C, 53.98; H, 3.83; N, 14.53. Found: C, 54.09; H, 4.11; N, 14.28.

$\boldsymbol{N}$-Acetyl- $\boldsymbol{N}^{\prime}$-(5-phenyl-2-furoyl)hydrazine (III-12-1). White solid: yield 75.6\%, m.p. 129-130 ${ }^{\circ} \mathrm{C}$. IR (KBr) $v_{\text {max }}: 3402.2,3223.5,3057.3,1643.5,1563.8,1464.3,1352.2,1253.9,1172.1,1034.5 \mathrm{~cm}^{-1}$. ${ }^{1} \mathrm{H}$ NMR (300 MHz, DMSO-d $\left.)_{6}\right) \delta: 2.16\left(\mathrm{~s}, 3 \mathrm{H}, \mathrm{CH}_{3}\right), 7.19(\mathrm{~d}, J=3.60 \mathrm{~Hz}, 1 \mathrm{H}, \mathrm{FuH}), 7.35(\mathrm{~d}$, $J=3.63 \mathrm{~Hz}, 1 \mathrm{H}, \mathrm{FuH}), 7.37-7.43$ (m, 1H, ArH-Fu), 7.47-7.52 (m, 2H, ArH-Fu), 7.97-8.00 (m, 2H, $\mathrm{ArH}-\mathrm{Fu}), 10.62(\mathrm{~s}, 1 \mathrm{H}, \mathrm{NH}), 10.64(\mathrm{~s}, 1 \mathrm{H}, \mathrm{NH}) . \mathrm{MS} / \mathrm{ESI}: m / e(\%) 245.1[\mathrm{M}+\mathrm{H}]^{+}$. Anal. Calcd. (\%) for $\mathrm{C}_{13} \mathrm{H}_{12} \mathrm{~N}_{2} \mathrm{O}_{3}$ : C, 63.93; H, 4.95; N, 11.47. Found: C, 64.06; H, 5.17; N, 11.28.

$\boldsymbol{N}$-Acetyl- $\boldsymbol{N}^{\prime}$-[5-(4'-methylphenyl)-2-furoyl]hydrazine (III-13-1). White solid: yield 73.5\%, m.p. $142-143{ }^{\circ} \mathrm{C}$. IR (KBr) $v_{\max }: 3423.3,3253.3,2875.8,1643.5,1583.4,1464.3,1274.5,1175.1$, $1043.2 \mathrm{~cm}^{-1} .{ }^{1} \mathrm{H}$ NMR $\left(300 \mathrm{MHz}, \mathrm{DMSO}-d_{6}\right) \delta: 2.16\left(\mathrm{~s}, 3 \mathrm{H}, \mathrm{CH}_{3}\right), 2.35\left(\mathrm{~s}, 3 \mathrm{H}, \mathrm{CH}_{3}\right), 7.10(\mathrm{~d}$, $J=3.60 \mathrm{~Hz}, 1 \mathrm{H}, \mathrm{FuH}), 7.27-7.33$ (m, 3H, FuH + 2ArH-Fu), 7.85-7.88 (m, 2H, ArH-Fu), 10.57 (s, $1 \mathrm{H}, \mathrm{NH}), 10.62(\mathrm{~s}, 1 \mathrm{H}, \mathrm{NH}) . \mathrm{MS} / \mathrm{ESI}: m / e(\%) 281.1[\mathrm{M}+\mathrm{Na}]^{+}$. Anal. Calcd. (\%) for $\mathrm{C}_{14} \mathrm{H}_{14} \mathrm{~N}_{2} \mathrm{O}_{3}$ : C, 65.11; H, 5.46; N, 10.85. Found: C, 65.25; H, 5.71; N, 10.64 .

$\boldsymbol{N}$-Acetyl- $\boldsymbol{N}^{\prime}$-[5-(4'-methoxyphenyl)-2-furoyl]hydrazine (III-14-1). White solid: yield 79.2\%, m.p. 137-138 ${ }^{\circ} \mathrm{C}$. IR (KBr) $v_{\max }: 3402.3$, 3243.2, 3012.2, 1635.8, 1574.5, 1454.4, 1383.1, 1289.5, 1216.7, 1142.1, $1064.5 \mathrm{~cm}^{-1} .{ }^{1} \mathrm{H}$ NMR (300 MHz, DMSO- $\left.d_{6}\right) \delta: 2.16\left(\mathrm{~s}, 3 \mathrm{H}, \mathrm{CH}_{3}\right), 3.82\left(\mathrm{~s}, 3 \mathrm{H}, \mathrm{OCH}_{3}\right)$, 7.01-7.07 (m, 3H, FuH + 2ArH-Fu), 7.30 (d, $J=3.60 \mathrm{~Hz}, 1 \mathrm{H}, \mathrm{FuH}), 7.90-7.93$ (m, 2H, ArH-Fu), $10.43(\mathrm{~s}, 1 \mathrm{H}, \mathrm{NH}), 10.49(\mathrm{~s}, 1 \mathrm{H}, \mathrm{NH}) . \mathrm{MS} / \mathrm{ESI}:$ m/e (\%) $275.1[\mathrm{M}+\mathrm{H}]^{+}$. Anal. Calcd. (\%) for $\mathrm{C}_{14} \mathrm{H}_{14} \mathrm{~N}_{2} \mathrm{O}_{4}$ : C, 61.31; H, 5.14; N, 10.21. Found: C, 61.11; H, 5.13; N, 10.04. 
$\boldsymbol{N}$-Acetyl- $\boldsymbol{N}^{\prime}$-[5-(4'-bromophenyl)-2-furoyl]hydrazine (III-15-1). White solid: yield 84.3\%, m.p. $160-161{ }^{\circ} \mathrm{C}$. IR (KBr) $v_{\max }: 3432.5$, 3074.3, 1645.4, 1584.5, 1521.7, 1463.6, 1365.1, 1212.4, 1175.1, $1032.9 \mathrm{~cm}^{-1} .{ }^{1} \mathrm{H}$ NMR (300 MHz, DMSO-d $) \delta: 2.15\left(\mathrm{~s}, 3 \mathrm{H}, \mathrm{CH}_{3}\right), 7.24(\mathrm{~d}, J=3.63 \mathrm{~Hz}, 1 \mathrm{H}$, $\mathrm{FuH}), 7.34(\mathrm{~d}, J=3.63 \mathrm{~Hz}, 1 \mathrm{H}, \mathrm{FuH}), 7.69-7.72(\mathrm{~m}, 2 \mathrm{H}, \mathrm{ArH}-\mathrm{Fu}), 7.94-7.97$ (m, 2H, ArH-Fu), 10.45 (s, 1H, NH), 10.73 (s, 1H, NH). MS/ESI: m/e (\%) $345.1[\mathrm{M}+\mathrm{Na}]^{+}$. Anal. Calcd. (\%) for $\mathrm{C}_{13} \mathrm{H}_{11} \mathrm{BrN}_{2} \mathrm{O}_{3}$ : C, 48.32; H, 3.43; N, 8.67. Found: C, 48.57; H, 3.28; N, 8.88.

$\boldsymbol{N}$-Propionyl- $\boldsymbol{N}^{\prime}$-[5-(4'-cholorophenyl)-2-furoyl]hydrazine (III-3-2). White solid: yield 81.6\%, m.p. $110-111{ }^{\circ} \mathrm{C}$. IR (KBr) $v_{\max }$ : 3418.1, 3213.5, 1691.3, 1632.1, 1591.2, 1520.3, 1481.3, 1280.6, 1211.3, $1121.4 \mathrm{~cm}^{-1}$. ${ }^{1} \mathrm{H}$ NMR (300 MHz, DMSO-d $)_{6} \delta: 1.12\left(\mathrm{t}, J=6.96 \mathrm{~Hz}, 3 \mathrm{H}, \mathrm{CH}_{3}-\mathrm{C}\right)$, $2.13\left(\mathrm{q}, J=6.96 \mathrm{~Hz}, 2 \mathrm{H}, \mathrm{CO}-\mathrm{CH}_{2}-\mathrm{C}\right), 7.35$ (d, $\left.J=3.69 \mathrm{~Hz}, 1 \mathrm{H}, \mathrm{FuH}\right), 7.40$ (d, $\left.J=3.72 \mathrm{~Hz}, 1 \mathrm{H}, \mathrm{FuH}\right)$, 7.42-7.54 (m, 2H, ArH-Fu), 7.61-7.64 (m, 1H, ArH-Fu), 8.25-8.28 (m, 1H, ArH-Fu), 10.48 (s, 1H, $\mathrm{NH}), 10.78(\mathrm{~s}, 1 \mathrm{H}, \mathrm{NH})$. MS/ESI: $m / e(\%) 293.1[\mathrm{M}+\mathrm{H}]^{+}$. Anal. Calcd. (\%) for $\mathrm{C}_{14} \mathrm{H}_{13} \mathrm{ClN}_{2} \mathrm{O}_{3}$ : C, 57.44; H, 4.48; N, 9.57. Found: C, 57.61; H, 4.28; N, 9.72.

$\boldsymbol{N}$-Butyryl- $\boldsymbol{N}^{\prime}$-[5-(4'-cholorophenyl)-2-furoyl]hydrazine (III-3-3). White solid: yield 78.3\%, m.p. 121-122 ${ }^{\circ} \mathrm{C}$. IR (KBr) $v_{\max }: 3415.6,3245.1,2934.3,1641.6,1604.5,1551.4,1478.5,1286.5$, 1253.6, 1146.2, 1173.6, $1015.7 \mathrm{~cm}^{-1} .{ }^{1} \mathrm{H}$ NMR (300 MHz, DMSO- $\left.d_{6}\right) \delta: 0.96(\mathrm{t}, J=7.50 \mathrm{~Hz}, 3 \mathrm{H}$, $\mathrm{CH}_{3}-\mathrm{C}$ ), 1.59-1.63 (m, 2H, C- $\left.\mathrm{CH}_{2}-\mathrm{C}\right), 2.19$ (t, $\left.J=7.56 \mathrm{~Hz}, 2 \mathrm{H}, \mathrm{C}-\mathrm{CH}_{2}-\mathrm{CO}\right), 7.33$ (d, $J=3.66 \mathrm{~Hz}$, 1H, FuH), 7.38 (d, $J=3.66 \mathrm{~Hz}, 1 \mathrm{H}, \mathrm{FuH}), 7.41-7.54$ (m, 2H, ArH-Fu), 7.60-7.63 (m, 1H, ArH-Fu), 8.22-8.25 (m, 1H, ArH-Fu), 10.32 (s, 1H, NH), 10.51 (s, 1H, NH). MS/ESI: $m / e(\%) 329.1[\mathrm{M}+\mathrm{Na}]^{+}$. Anal. Calcd. (\%) for $\mathrm{C}_{15} \mathrm{H}_{15} \mathrm{ClN}_{2} \mathrm{O}_{3}: \mathrm{C}, 58.73 ; \mathrm{H}, 4.93 ; \mathrm{N}, 9.13$. Found: C, 58.52; H, 5.06; N, 9.31 .

$\boldsymbol{N}$-Isobutyryl- $\boldsymbol{N}^{\prime}$-[5-(4'-cholorophenyl)-2-furoyl]hydrazine (III-3-4). White solid: yield 82.0\%, m.p. $128-129{ }^{\circ} \mathrm{C}$. IR (KBr) $v_{\max }: 3418.4,3250.3,1681.6,1646.7,1592.4,1523.5,1493.1,1253.5$, $1181.2,1110.7 \mathrm{~cm}^{-1} .{ }^{1} \mathrm{H}$ NMR $\left(300 \mathrm{MHz}, \mathrm{DMSO}-d_{6}\right) \delta: 0.86\left(\mathrm{~d}, 6 \mathrm{H}, J=7.02 \mathrm{~Hz},\left(\mathrm{CH}_{3}\right)_{2} \mathrm{C}\right), 2.11-2.14$ (m, 1H, CO-CH-C), 7.33 (d, $J=3.69 \mathrm{~Hz}, 1 \mathrm{H}, \mathrm{FuH}), 7.38$ (d, $J=3.69 \mathrm{~Hz}, 1 \mathrm{H}, \mathrm{FuH}), 7.41-7.54$ (m, 2H, ArH-Fu), 7.61-7.64 (m, 1H, ArH-Fu), 8.22-8.25 (m, 1H, ArH-Fu), 10.34 (s, 1H, NH), 10.58 (s, 1H, NH). MS/ESI: $m / e(\%) 307.2[\mathrm{M}+\mathrm{H}]^{+}$. Anal. Calcd. (\%) for $\mathrm{C}_{15} \mathrm{H}_{15} \mathrm{ClN}_{2} \mathrm{O}_{3}$ : C, 58.73; H, 4.93; N, 9.13. Found: C, 58.90; H, 4.81; N, 9.29.

$\boldsymbol{N}$-Hexanoyl- $\boldsymbol{N}^{\prime}$-[5-(4'-cholorophenyl)-2-furoyl]hydrazine (III-3-5). White solid: yield 78.0\%, m.p. $140-141{ }^{\circ} \mathrm{C}$. IR (KBr) $v_{\max }$ : 3399.4, 3213.6, 2887.4, 1621.4, 1591.6, 1534.7, 1491.5, 1474.3, 1271.8, $1111.5 \mathrm{~cm}^{-1} .{ }^{1} \mathrm{H}$ NMR (300 MHz, DMSO- $\left.d_{6}\right) \delta: 0.94\left(\mathrm{t}, J=7.52 \mathrm{~Hz}, 3 \mathrm{H}, \mathrm{CH}_{3}\right), 1.32-1.35$ (m, 2H, $\left.\mathrm{CH}_{2}\right), 1.64-1.67\left(\mathrm{~m}, 2 \mathrm{H}, \mathrm{CH}_{2}\right), 2.09-2.12\left(\mathrm{~m}, 2 \mathrm{H}, \mathrm{CH}_{2}\right), 2.20$ (t, $\left.J=7.8 \mathrm{~Hz}, 2 \mathrm{H}, \mathrm{C}-\mathrm{CH}_{2}-\mathrm{CO}\right)$, $7.34(\mathrm{~d}, J=3.69 \mathrm{~Hz}, 1 \mathrm{H}, \mathrm{FuH}), 7.39(\mathrm{~d}, J=3.69 \mathrm{~Hz}, 1 \mathrm{H}, \mathrm{FuH}), 7.42-7.54(\mathrm{~m}, 2 \mathrm{H}, \mathrm{ArH}-\mathrm{Fu})$, 7.60-7.63 (m, 1H, ArH-Fu), 8.21-8.24 (m, 1H, ArH-Fu), 10.64 (s, 1H, NH), 10.66 (s, 1H, NH). MS/ESI: $m / e(\%) 335.1[\mathrm{M}+\mathrm{H}]^{+}$. Anal. Calcd. (\%) for $\mathrm{C}_{17} \mathrm{H}_{19} \mathrm{ClN}_{2} \mathrm{O}_{3}$ : C, 60.99; $\mathrm{H}, 5.72 ; \mathrm{N}, 8.37$. Found: C, 61.13; H, 5.84; N, 8.45.

$\boldsymbol{N}$-Heptanoyl- $\boldsymbol{N}^{\prime}$-[5-(4'-cholorophenyl)-2-furoyl]hydrazine (III-3-6). White solid: yield 80.5\%, m.p. 143-144 ${ }^{\circ} \mathrm{C}$. IR (KBr) $v_{\max }$ : 3416.9, 3221.2, 2884.1, 1632.1, 1572.1, 1524.7, 1484.3, 1254.8, 1233.5, $1105.3 \mathrm{~cm}^{-1} .{ }^{1} \mathrm{H}$ NMR (300 MHz, DMSO-d $) \delta: 0.94\left(\mathrm{t}, 3 \mathrm{H}, J=7.50 \mathrm{~Hz}, \mathrm{CH}_{3}\right), 1.24-1.29$ (m, $\left.6 \mathrm{H}, 3 \mathrm{CH}_{2}\right), 1.54-1.57\left(\mathrm{~m}, 2 \mathrm{H}, \mathrm{CH}_{2}\right), 2.15-2.17\left(\mathrm{~m}, 2 \mathrm{H}, \mathrm{C}-\mathrm{CH}_{2}-\mathrm{CO}\right), 7.34(\mathrm{~d}, J=3.69 \mathrm{~Hz}, 1 \mathrm{H}, \mathrm{FuH})$, $7.39(\mathrm{~d}, J=3.69 \mathrm{~Hz}, 1 \mathrm{H}, \mathrm{FuH}), 7.42-7.55$ (m, 2H, ArH-Fu), 7.60-7.63 (m, 1H, ArH-Fu), 8.22-8.25 
(m, 1H, ArH-Fu), 10.55 (s, 1H, NH), 10.68 (s, 1H, NH). MS/ESI: m/e (\%) $349.1[\mathrm{M}+\mathrm{H}]^{+}$. Anal. Calcd. (\%) for $\mathrm{C}_{18} \mathrm{H}_{21} \mathrm{ClN}_{2} \mathrm{O}_{3}$ : C, 61.98; H, 6.07; N, 8.03. Found: C, 62.16; H, 6.18; N, 7.93.

$\boldsymbol{N}$-Octanoyl- $\boldsymbol{N}^{\prime}$-[5-(4'-cholorophenyl)-2-furoyl]hydrazine (III-3-7). White solid: yield 82.5\%, m.p. $149-150{ }^{\circ} \mathrm{C}$. IR (KBr) $v_{\max }: 3398.5,3114.7,1607.5,1492.5,1451.7,1250.6,1221.1 \mathrm{~cm}^{-1}$. ${ }^{1} \mathrm{H}$ NMR (300 MHz, DMSO- $\left.d_{6}\right) \delta: 0.96\left(\mathrm{t}, 3 \mathrm{H}, J=7.50 \mathrm{~Hz}, \mathrm{CH}_{3}\right), 1.26-1.30\left(\mathrm{~m}, 8 \mathrm{H}, 4 \mathrm{CH}_{2}\right), 1.56-1.59$ (m, 2H, $\mathrm{CH}_{2}$ ), 2.17-2.19 (m, 2H, C- $\left.\mathrm{CH}_{2}-\mathrm{CO}\right), 7.34$ (d, J=3.69 Hz, 1H, FuH), 7.39 (d, J=3.69 Hz, 1H, FuH), 7.42-7.55 (m, 2H, ArH-Fu), 7.60-7.63 (m, 1H, ArH-Fu), 8.22-8.25 (m, 1H, ArH-Fu), $10.53(\mathrm{~s}, 1 \mathrm{H}, \mathrm{NH}), 10.64(\mathrm{~s}, 1 \mathrm{H}, \mathrm{NH}) . \mathrm{MS} / \mathrm{ESI}: m / e(\%) 363.2[\mathrm{M}+\mathrm{H}]^{+}$. Anal. Calcd. (\%) for $\mathrm{C}_{19} \mathrm{H}_{23} \mathrm{ClN}_{2} \mathrm{O}_{3}$ : C, 62.89; H, 6.39; N, 7.72. Found: C, 63.06; H, 6.25; N, 7.60.

$\boldsymbol{N}$-Nonanoyl- $\boldsymbol{N}$ '-[5-(4'-cholorophenyl)-2-furoyl]hydrazine (III-3-8). White solid: yield 80.8\%, m.p. $159-160{ }^{\circ} \mathrm{C}$. IR (KBr) $v_{\max }: 3410.4,3206.7,2931.3,1620.5,1617.5,1532.6,1484.6,1369.4$, 1289.3, $1110.3 \mathrm{~cm}^{-1} .{ }^{1} \mathrm{H}$ NMR (300 MHz, DMSO- $\left.d_{6}\right) \delta: 0.93\left(\mathrm{t}, J=7.50 \mathrm{~Hz}, 3 \mathrm{H}, \mathrm{CH}_{3}\right), 1.28-1.33(\mathrm{~m}$, $\left.10 \mathrm{H}, 5 \mathrm{CH}_{2}\right), 1.58-1.60\left(\mathrm{~m}, 2 \mathrm{H}, \mathrm{CH}_{2}\right), 2.21(\mathrm{t}, 2 \mathrm{H}, J=7.50 \mathrm{~Hz}),, 7.33(\mathrm{~d}, J=3.66 \mathrm{~Hz}, 1 \mathrm{H}, \mathrm{FuH}), 7.39$ (d, $J=3.69 \mathrm{~Hz}, 1 \mathrm{H}, \mathrm{FuH}), 7.41-7.54$ (m, 2H, ArH-Fu), 7.60-7.63 (m, 1H, ArH-Fu), 8.22-8.25 (m, 1H, ArH-Fu), 10.47 (s, 1H, NH), $10.62(\mathrm{~s}, 1 \mathrm{H}, \mathrm{NH})$. MS/ESI: m/e (\%) $377.3[\mathrm{M}+\mathrm{H}]^{+}$. Anal. Calcd. (\%) for $\mathrm{C}_{20} \mathrm{H}_{25} \mathrm{ClN}_{2} \mathrm{O}_{3}$ : C, 63.74; H, 6.69; N, 7.43. Found: C, 63.58; H, 6.83; N, 7.27.

$\boldsymbol{N}$-Decanoyl- $\boldsymbol{N}$ '-[5-(4'-cholorophenyl)-2-furoyl]hydrazine (III-3-9). White solid: yield 78.2\%, m.p. $162-163{ }^{\circ} \mathrm{C}$. IR (KBr) $v_{\max }: 3397.1,3212.4,2962.4,1631.5,1527.3,1478.9,1295.7 \mathrm{~cm}^{-1}$. ${ }^{1} \mathrm{H}$ NMR (300 MHz, DMSO-d $) \delta: 0.90(\mathrm{t}, 3 \mathrm{H}, J=6.5 \mathrm{~Hz}, \mathrm{H}-9), 1.27-1.32\left(\mathrm{~m}, 12 \mathrm{H}, 5 \mathrm{CH}_{2}\right), 1.59-1.61$ (m, 2H, $\mathrm{CH}_{2}$ ), 2.19-2.21 (m, 2H, C- $\left.\mathrm{CH}_{2}-\mathrm{CO}\right), 7.33$ (d, $\left.J=3.66 \mathrm{~Hz}, 1 \mathrm{H}, \mathrm{FuH}\right), 7.39$ (d, J=3.69 Hz, 1H, FuH), 7.41-7.54 (m, 2H, ArH-Fu), 7.60-7.63 (m, 1H, ArH-Fu), 8.22-8.25 (m, 1H, ArH-Fu), $10.46(\mathrm{~s}, 1 \mathrm{H}, \mathrm{NH}), 10.60(\mathrm{~s}, 1 \mathrm{H}, \mathrm{NH}) . \mathrm{MS} / \mathrm{ESI}: m / e(\%) 413.2[\mathrm{M}+\mathrm{Na}]^{+}$. Anal. Calcd. (\%) for $\mathrm{C}_{21} \mathrm{H}_{27} \mathrm{ClN}_{2} \mathrm{O}_{3}$ : C, 64.52; H, 6.96; N, 7.17. Found: C, 64.71; H, 7.10; N, 6.99.

\subsection{Crystallography}

Compound III-3-2 was recrystallized from methanol to give colorless crystals suitable for X-ray single crystal diffraction. Cell constants at 113(2) K were determined by a least-square fit to the setting parameters of independent reflections measured on a Bruker SMART [12] 1000 CCD area-detector diffractometer (Bruker, Fallanden, Switzerland) with graphite-monochromated Mo $\mathrm{K}_{\alpha}$ radiation $(\lambda=0.071070 \mathrm{~nm})$ and operating in the phi and scan modes. The structure was solved by the direct method with SHELXS-97 [24-27] and refined by the full-matrix least squares method on F2 data using SHELXL-97 [27,28]. The empirical absorption corrections were applied to all intensity data. $\mathrm{H}$ atom of $\mathrm{N}-\mathrm{H}$ was initially located in a different Fourier map and was refined with the restraint $U_{\text {iso }}(\mathrm{H})=1.2 U_{\text {eq }}(\mathrm{N})$. Other $\mathrm{H}$ atoms were positioned geometrically and refined using a riding model, with $d(\mathrm{C} \cdots \mathrm{H})=0.093-0.097 \mathrm{~nm}$ and $U_{\text {iso }}(\mathrm{H})=1.2 U_{\text {eq }}(\mathrm{C})$ or $1.5 U_{\text {eq }}(\mathrm{C}-$ methyl). The crystal data in CIF format have been deposited at the Cambridge Crystallographic Data Centre with deposition number CCDC 935116. 


\subsection{Bioassay}

\subsubsection{Insecticidal Activity}

Assessments were made on a dead/live basis. Evaluations are based on a percentage scale of $0-100$, which 0 equals no activity and 100 equals total kill. The bioassay was repeated three times and the result of bioactivity was the average of these replicates. Error in the experiments was 5\%. The commercialized insecticide RH-5849 and an aromatic derivative (Scheme 1, VI-1: $\mathrm{R}^{1}=4-\mathrm{CH}_{3}$, $\mathrm{R}^{2}=4-\mathrm{Cl}$ ) were tested as controls under the same conditions. EXCEL2007 was applied to analyze bioassay data.

Larvicidal activity against Culex pipiens pallens. The larvicidal activity was evaluated at the preliminary test concentration of $10 \mathrm{mg} \cdot \mathrm{L}^{-1}$ against the fourth-instar Culex pipiens pallens by the water immersion method under conditions of $27 \pm 2{ }^{\circ} \mathrm{C}$, photoperiod of 10:14 (light:dark), and relative humidity $50 \%-70 \%$. All the test beakers containing twenty Culex pipiens pallens were evaluated 8 days after treatment.

Larvicidal activity against the oriental armyworm (Mythimna separata). The larvicidal activity of the title compounds against the oriental armyworm was evaluated by foliar application. For the foliar armyworm tests, individual corn leaves were placed on moistened pieces of filter paper in Petri dishes. The leaves were then sprayed with the test solution at the preliminary test concentration of $200 \mathrm{mg} \cdot \mathrm{L}^{-1}$ and allowed to dry. The dishes were infested with 10 fourth-instar oriental armyworm larvae. Percentage mortalities were evaluated 4 days after treatment.

Larvicidal activity against the diamondback moth (Plutella xylostella). The larvicidal activity of the title compounds against the diamondback moth was tested by the leaf-dip method. Leaf disks (1.8 cm diameter) were cut from fresh cabbage leaves and then dipped in the test solution for $15 \mathrm{~s}$ at the preliminary test concentration of $200 \mathrm{mg} \cdot \mathrm{L}^{-1}$. After air-drying, the treated leaf disks were placed in a Petri dish (9 $\mathrm{cm}$ diameter), lined with a piece of filter paper and then 10 second-instar diamondback moth larvae were transferred to the Petri dish. Percentage mortalities were evaluated 6 days after treatment.

\subsubsection{Fungicidal Activity}

Using pot culture tests according to references [12,26], the in vivo fungicidal activities of the title compounds against B. cinerea, $C$. cassiicola, F. oxysporum, and $R$. solanii were evaluated in a greenhouse with four commercial fungicides, 40\% pyrimethanil SC, 75\% chlorothalonil WP, 40\% flusilazole EC, and 3\% validamycin AS and an aromatic derivative (Scheme 1, VI-1: $\mathrm{R}^{1}=4-\mathrm{CH}_{3}$, $\mathrm{R}^{2}=4-\mathrm{Cl}$ ) as controls. All the strains were conserved at the Institute of Plant Protection, Chinese Academy of Agricultural Science, Beijing, China. B. cinerea, C. cassiicola, F. oxysporum, and $R$. solanii were maintained on potato dextrose agar (PDA) medium at $4{ }^{\circ} \mathrm{C}$. The culture plates were cultivated at $24 \pm 1{ }^{\circ} \mathrm{C}$. Germination was conducted by soaking cucumber seeds in water for $2 \mathrm{~h}$ at $50{ }^{\circ} \mathrm{C}$ and then keeping the seeds moist for $24 \mathrm{~h}$ at $28{ }^{\circ} \mathrm{C}$ in an incubator. When the radicles were $0.5 \mathrm{~cm}$, the seeds were grown in plastic pots containing a $1: 1(\mathrm{v} / \mathrm{v})$ mixture of vermiculite and peat. Cucumber plants used for inoculations were at the stage of two seed leaves.

Tested compounds and commercial fungicides were sprayed with a hand spray onto the surface of the seed leaves and were used for B. cinerea, $C$. cassiicola, and $R$. solanii at the standard concentration 
of $500 \mu \mathrm{g} \cdot \mathrm{mL}^{-1}$. Tested compounds and commercial fungicide were applied to the cucumber plants by the irrigating method and used for $F$. oxysporum. Three replicates were used per treatment.

After drying, inoculation of $C$. cassiicola was carried out by spraying a conidial suspension, $F$. oxysporum was innoculated by embryo root inoculation, while inoculations of $B$. cinerea and $R$. solanii were carried out by spraying mycelial suspensions. Three replicates were performed. After inoculation, the plants were maintained at $24 \pm 1{ }^{\circ} \mathrm{C}$ and above $80 \%$ relative humidity.

The fungicidal activity was evaluated when the untreated cucumber plant (blank control) fully developed symptoms. The area of inoculated treated leaves covered by disease symptoms was assessed and compared to that of untreated ones to determine the average disease index. The relative control efficacy of compounds compared to the blank assay was calculated via Equation (1):

$$
I(\%)=[(C K-P T) / C K] \times 100 \%
$$

where $I$ is relative control efficacy, $C K$ is the average disease index during the blank assay, and $P T$ is the average disease index after treatment during testing.

\subsubsection{Anti-Tumor Activity}

All the title compounds were dissolved in DMSO and screened for preliminary anti-tumor activity against four different cell lines: a human promyelocytic leukemic cell line (HL-60), a human hepatocellular carcinoma cell line (Bel-7402), a human gastric carcinoma cell line (BGC-823), and a human nasopharyngeal carcinoma cell line $(\mathrm{KB})$ at a concentration gradient of $0.1,1.0,10,50$, and $100 \mu \mathrm{M}$. The commercial drug doxorubicin and an aromatic derivative (Scheme 1, VI-1: $\mathrm{R}^{1}=4-\mathrm{CH}_{3}$, $\mathrm{R}^{2}=4-\mathrm{Cl}$ ) were used as controls in the bioassay. Three replicates were performed.

The four types of cell line were grown and maintained in RPMI-1640 medium supplemented with $10 \%$ fetal bovine serum (FBS), penicillin $\left(100 \mathrm{U} \cdot \mathrm{mL}^{-1}\right)$, and streptomycin $\left(100 \mu \mathrm{g} \cdot \mathrm{mL}^{-1}\right)$ at $37{ }^{\circ} \mathrm{C}$ in humidified incubators in an atmosphere of $5 \% \mathrm{CO}_{2}$.

All the experiments were performed on exponentially growing cancer cells. Numbers of viable cancer cells were determined by MTT [3-(4,5-dimethylthiazol-2-yl)-2,5-diphenyl tetrazoliumbromide] [27] and SRB (sulforhodamine B) [28] assays. The cancer cells $\left((1-2.5) \times 10^{4}\right.$ cells $\left.\cdot \mathrm{mL}^{-1}\right)$ were inoculated in 96-well culture plates (180 $\mu \mathrm{L} /$ well). After $24 \mathrm{~h}, 20 \mu \mathrm{L}$ of culture medium containing compounds of various concentrations were added to the wells and the cells were incubated for $48 \mathrm{~h}$. to control cells, $20 \mu \mathrm{L}$ of RPMI-1640 medium was added. HL-60 cells were assayed by MTT, whereas Bel-7402, BGC-823, and KB cells were assayed by SRB. The absorbance of each well was measured using a microculture plate reader at $570 \mathrm{~nm}$ (MTT) and $540 \mathrm{~nm}(\mathrm{SRB})$, respectively. The inhibition rate was calculated according to Equation (2):

$$
\text { Inhibition rate }=\left(O D_{\text {control }}-O D_{\text {treated }}\right) / O D_{\text {control }} \times 100 \%
$$

\section{Conclusions}

In summary, a series of novel 5-substituted-2-furoyl diacylhydazide derivatives with aliphatic chain III was designed and synthesized. Their anti-tumor and anti-fungal tests indicated that most of the title compounds showed significant bioactivity against the tested tumor cell lines and fungi. The bioactivity was improved and better than that of the aromatic diacylhydrazides. The aliphatic chain length and 
the structure and position of the $\mathrm{R}^{2}$ group had a significant impact on the bioactivities. Generally, the shorter the chain, the better the corresponding activity was. When $\mathrm{R}^{2}$ was an electron-withdrawing group, such as $\mathrm{NO}_{2}$ and $\mathrm{Cl}$ at the ortho or para position, the compounds exhibited higher activity. While the electron-donating groups at the para or meta position on the phenyl ring decreased the activity. The title compounds with aliphatic chains exhibited moderate or marginal insecticidal activity, which was neither improved nor decreased compared to that of the aromatic diacylhydrazides.

\section{Acknowledgments}

We are very grateful to Marc David Upton for his salutary contribution to language polishing and manuscript melioration. We greatly acknowledge the financial support of this work by the National Natural Science Foundation of China (21102173), the State Key Laboratory for Biology of Plant Diseases and Insect Pests (SKLOF201411), and the President Science Foundation of South China Agricultural University (4200-K13014).

\section{Author Contributions}

Conceived and designed the experiments: Z.C. and X.Y. Performed the experiments: Z.C., X.L., and X.Y. Analyzed the data: Z.C. and F.T. Wrote the paper: Z.C.

\section{Conflicts of Interest}

The authors declare no conflict of interest.

\section{References}

1. Fox, H.H. Chemical approach to the control of tuberculosis. Science 1952, 116, 129-134.

2. Magliozzo, R.S.; Marcinkeviciene, J.A. Evidence for isoniazid oxidation by oxyferrous mycobacterial catalase-peroxidase. J. Am. Chem. Soc. 1996, 118, 11303-11304.

3. Joshi, S.D.; More, Y.; Vagdevi, H.M.; Vaidya, V.P.; Gadaginamath, G.S.; Kulkarni, V.H. Synthesis of new 4-(2,5-dimethylpyrrol-1-yl)/4-pyrrol-1-ylbenzoic acid hydrazide analogs and some derived oxadiazole, triazole and pyrrole ring systems: A novel class of potential antibacterial, antifungal and antitubercular agents. Med. Chem. Res. 2013, 22, 1073-1089.

4. Vigorita, M.G.; Maccari, R.; Ottana, R.; Monforte, F. Lipophilic analogs of isoniazid with antiproliferative in vitro activity-VIII. Med. Chem. Res. 1999, 9, 306-321.

5. Sechi, M.; Azzena, U.; Delussu, M.P.; Dallocchio, R.; Dessi, A.; Cosseddu, A.; Pala, N.; Neamati, N. Design and synthesis of bis-amide and hydrazide-containing derivatives of malonic acid as potential HIV-1 integrase inhibitors. Molecules 2008, 13, 2442-2461.

6. Arvadia, P.; Narwaley, M.; Whittal, R.M.; Siraki, A.G. 4-Aminobenzoic acid hydrazide inhibition of microperoxidase-11: Catalytic inhibition by reactive metabolites. Arch. Biochem. Biophys. 2011, 515, 120-126. 
7. Watson, K.A.; Mitchell, E.P.; Johnson, L.N.; Son, J.C.; Bichard, C.J.F.; Orchard, M.G.; Fleet, G.W.J.; Oikonomakos, N.G.; Leonidas, D.D.; Kontou, M.; et al. Design of inhibitors of glycogen phosphorylase: A study of $\alpha$ - and $\beta$ - $C$-glucosides and 1-thio- $\beta$-D-glucose compounds. Biochemistry 1994, 33, 5745-5758.

8. Wing, K.D. RH 5849, a nonsteroidal ecdysone agonist: Effects on a Drosophila cell line. Science 1988, 241, 467-469.

9. Wing, K.D.; Slawecki, R.A.; Carlson, G.R. RH 5849, a nonsteroidal ecdysone agonist: Effects on larval Lepidoptera. Science 1988, 241, 470-472.

10. Cowles, R.S.; Villani, M.G. Susceptibility of Japanese beetle, Oriental beetle, and European chafer (Coleoptera: Scarabaeidae) to halofenozide, an insect growth regulator. J. Econ. Entomol. 1996, 89, 1356-1365.

11. Moulin, A.; Bibian, M.; Blayo, A.-L.; El Habnouni, S.; Martinez, J.; Fehrentz, J.-A. Synthesis of 3,4,5-trisubstituted-1,2,4-triazoles. Chem. Rev. 2010, 110, 1809-1827.

12. Cui, Z.N.; Shi, Y.X.; Zhang, L.; Ling, Y.; Li, B.J.; Nishida, Y.; Yang, X.L. Synthesis and fungicidal activity of novel 2,5-disubstituted-1,3,4-oxadiazole derivatives. J. Agric. Food Chem. 2012, 60, 11649-11656.

13. Cui, Z.N.; Yang, L.; Li, X.C.; Wang, Z.; Yang, X.L. Progress in the study on the synthesis and the activities as insect growth regulators of 2,5-disubstituted 1,3,4-oxadiazoles. Chin. J. Org. Chem. 2006, 26, 1647-1656.

14. Nagendra, G.; Lamani, R.S.; Narendra, N.; Sureshbabu, V.V. A convenient synthesis of 1,3,4-thiadiazole and 1,3,4-oxadiazole based peptidomimetics employing diacylhydrazines derived from amino acids. Tetrahedron Lett. 2010, 51, 6338-6341.

15. Saracoglu, N. Recent advances and applications in 1,2,4,5-tetrazine chemistry. Tetrahedron 2007, 63, 4199-4236.

16. Cui, Z.N.; Yang, X.L.; Shi, Y.X.; Uzawa, H.; Cui, J.R.; Dohi, H.; Nishida, Y. Molecular design, synthesis and bioactivity of glycosyl hydrazine and hydrazone derivatives: Notable effects of the sugar moiety. Bioorg. Med. Chem. Lett. 2011, 21, 7193-7196.

17. Cui, Z.N.; Zhang, L.; Huang, J.; Yang, X.L.; Ling, Y. Synthesis and bioactivity of novel $N, N^{\prime}$-diacylhydrazine derivatives containing furan(III). Chin. J. Chem. 2010, 28, 1257-1266.

18. Cui, Z.N.; Zhang, L.; Huang, J.; Ling, Y.; Yang, X.L. Synthesis, insecticidal activity and 3D-QSAR studies on diacylhydrazine derivatives containing furan. Chin. J. Org. Chem. 2010, 30, 1482-1491.

19. Zhang, L.; Cui, Z.N.; Yin, B.; Yang, G.F.; Ling, Y.; Yang, X.L. QSAR and 3D-QSAR studies of the diacyl-hydrazine derivatives containing furan rings based on the density functional theory. Sci. China Chem. 2010, 53, 1322-1331.

20. Li, X.C.; Yang, X.L.; Cui, Z.N.; Li, Y.; He, H.W.; Ling, Y. Synthesis and bioactivity of novel $N, N^{\prime}$-diacylhydrazine derivatives containing furan(II). Chin. J. Chem. 2010, 28, 1233-1239.

21. Cui, Z.N.; Huang, J.; Li, Y.; Ling, Y.; Yang, X.L.; Chen, F.H. Synthesis and bioactivity of novel $N, N^{\prime}$-diacylhydrazine derivatives containing furan(I). Chin. J. Chem. 2008, 26, 916-922.

22. Cui, Z.N.; Wang, Z.; Li, Y.; Zhou, X.Y.; Ling, Y.; Yang, X.L. Synthesis of 5-(chlorophenyl)2-furancarboxylic acid 2-(benzoyl)hydrazide derivatives and determination of their insecticidal activity. Chin. J. Org. Chem. 2007, 27, 1300-1304. 
23. Cui, Z.N.; Li, Y.; Huang, J.; Ling, Y.; Cui, J.R.; Wang, R.Q.; Yang, X.L. New class of potent antitumor acylhydrazone derivatives containing furan. Eur. J. Med. Chem. 2010, 45, 5576-5584

24. Li, X.H.; Cui, Z.N.; Chen, X.Y.; Wu, D.C.; Qi, Z.Q.; Ji, M.S. Synthesis of 2-acyloxycyclohexyl sulfonamides and evaluation on their fungicidal activity, Int. J. Mol. Sci. 2013, 14, 22544-22557.

25. Li, X.H.; Pan, Q.; Cui, Z.N.; Ji, M.S.; Qi, Z.Q. Synthesis and fungicidal activity of $\mathrm{N}$-(2,4,5-trichlorophenyl)-2-oxo-and 2-hydroxycycloalkylsulfonamides. Lett. Drug Des. Discov. 2013, 10, 353-359.

26. Cui, Z.N.; Shi, Y.X.; Cui, J.R.; Ling, Y.; Li, B.J.; Yang, X.L. Synthesis and bioactivities of novel pyrazole and triazole derivatives containing 5-phenyl-2-furan. Chem. Biol. Drug Des. 2012, 79, 121-127.

27. Denizot, F.; Lang, R. Rapid colorimetric assay for cell growth and survival. Modifications to the tetrazolium dye procedure giving improved sensitivity and reliability. J. Immunol. Methods 1986, 89, 271-277.

28. Monks, A.; Scudiero, D.; Skehan, P.; Shoemaker, R.; Paull, K.; Vistica, D.; Hose, C.; Langley, J.; Cronise, P.; Vaigro-Wolff, A.; et al. Feasibility of a high-flux anticancer drug screen using a diverse panel of cultured human tumor cell lines. J. Natl. Cancer Inst. 1991, 83, 757-766.

(C) 2014 by the authors; licensee MDPI, Basel, Switzerland. This article is an open access article distributed under the terms and conditions of the Creative Commons Attribution license (http://creativecommons.org/licenses/by/3.0/). 